\title{
The forced oscillation technique in clinical practice: methodology, recommendations and future developments
}

\author{
E. Oostveen*, D. MacLeod ${ }^{\#}$, H. Lorino $₫$, R. Farré ${ }^{+}$, Z. Hantos ${ }^{\S}$, K. Desager $^{f}$, F. Marchal**, \\ on behalf of the ERS Task Force on Respiratory Impedance Measurements
}

The forced oscillation technique in clinical practice: methodology, recommendations and future developments. E. Oostveen, D. MacLeod, H. Lorino, R. Farré, Z. Hantos, $K$. Desager, F. Marchal, on behalf of the ERS Task Force on Respiratory Impedance Measurements. (C) ERS Journals Ltd 2003.

ABSTRACT: The forced oscillation technique (FOT) is a noninvasive method with which to measure respiratory mechanics. FOT employs small-amplitude pressure oscillations superimposed on the normal breathing and therefore has the advantage over conventional lung function techniques that it does not require the performance of respiratory manoeuvres.

The present European Respiratory Society Task Force Report describes the basic principle of the technique and gives guidelines for the application and interpretation of FOT as a routine lung function test in the clinical setting, for both adult and paediatric populations.

FOT data, especially those measured at the lower frequencies, are sensitive to airway obstruction, but do not discriminate between obstructive and restrictive lung disorders. There is no consensus regarding the sensitivity of FOT for bronchodilation testing in adults. Values of respiratory resistance have proved sensitive to bronchodilation in children, although the reported cutoff levels remain to be confirmed in future studies.

Forced oscillation technique is a reliable method in the assessment of bronchial hyperresponsiveness in adults and children. Moreover, in contrast with spirometry where a deep inspiration is needed, forced oscillation technique does not modify the airway smooth muscle tone. Forced oscillation technique has been shown to be as sensitive as spirometry in detecting impairments of lung function due to smoking or exposure to occupational hazards. Together with the minimal requirement for the subject's cooperation, this makes forced oscillation technique an ideal lung function test for epidemiological and field studies. Novel applications of forced oscillation technique in the clinical setting include the monitoring of respiratory mechanics during mechanical ventilation and sleep. Eur Respir J 2003; 22: 1026-1041.
*Dept of Pulmonary Medicine, University Hospital Antwerp, Belgium. ${ }^{\#}$ Scottish Intercollegiate Research Training Network, NHS Education for Scotland, UK. 'Service de Physiologie, Hôpital Henri Mondor, CréteilParis, France. ${ }^{+}$Unitat de Biof ísica i Bioenginyeria, Facultat de Medicina, Barcelona, Spain. ${ }^{\S}$ Dept of Medical Informatics, University of Szeged, Hungary. ${ }^{f}$ Dept of paediatrics, University Hospital Antwerp, Belgium. **Laboratoire d'Explorations Fonctionnelles Pediatriques, Hopital d'Enfants, CHU de Nancy, Vandoeuvre, France.

Correspondence: E. Oostveen, Dept of Pulmonary Medicine, University Hospital Antwerp, Wilrijkstraat $10, \quad$ B-2650 Edegem-Antwerp, Belgium.

Fax: 3238214447

E-mail: Ellie.Oostveen@uza.be

Keywords: Forced oscillations, guidelines, respiratory impedance, respiratory mechanics, respiratory resistance, standardisation

Received: August 42003

Accepted: August 62003

\section{CONTENTS}

Methodology . . . . . . . . . . . . . . . 1027

Potential and limitations . . . . . . . . . . . . 1027

Respiratory impedance . . . . . . . . . . . . . . . . . . . . 1027

Measurement arrangements . . . . . . . . . . . . . . . . . . . . . . . . . . . . . .

Oscillation frequencies. . . . . . . . . . . . . . 1027

Recommendations for measurements . . . . . . 1028

Set-up . . . . . . . . . . . . . . . . . . . 1028

Apparatus . . . . . . . . . . . . . . . . . . 1028

Calibration . . . . . . . . . . . . . . . . . 1028

Input signals. . . . . . . . . . . . . . . . . . . 1028

Signal processing. . . . . . . . . . . . . . . . . . . . . . . . . . . . . . . . . . . . . . . . . . .

Report of results . . . . . . . . . . . . . . . . . . . . 1029

Measurement conditions . . . . . . . . . . . . . 1029

The upper airway artefact . . . . . . . . . . . 1029

Clinical applications ................ 1030

As a tool for the investigation of respiratory mechanics in clinical practice, the forced oscillation technique (FOT) is well supported theoretically and has the advantage of being a noninvasive, versatile method and demanding minimal
Reference values . . . . . . . . . . . . . . . . . . . . . . . . . 1030

Reproducibility . . . . . . . . . . . . . . . . . . . . . . . 1030

Diagnostic capacity. . . . . . . . . . . . . . . . . . . . . . . . . . . . . . . . .

Follow-up and field studies . . . . . . . . . . . . . 1032

Identification of airway reactivity . . . . . . . . . . . . . . . . . . . . . . . . . . . . .

Reversibility . . . . . . . . . . . . . . . . . . 1033

Bronchial hyperresponsiveness . . . . . . . . . . 1034

Forced oscillation technique in

infancy ...................... 1035

New developments. . . . . . . . . . . . . . 1035

Applications of the forced oscillation technique in

monitoring respiratory mechanics . . . . . . . . . . 1035

Low-frequency oscillations. . . . . . . . . . . . 1035

High-frequency oscillations . . . . . . . . . . . . . . . . . . . . . . . . . . .

Conclusions ....................... 1036

cooperation of the patient. The most attractive feature of FOT is that the forced oscillations are superimposed on the normal breathing, avoiding the need for any special breathing manoeuvre or any noticeable interference with respiration. 
During the past decade, advances in basic research and FOT applications, as well as new developments in technology, have evoked new interest from both the clinical and industrial fields. To address demands for further standardisation of FOT, a European Respiratory Society Task Force was established to update the standardisation work carried out during the Commission of the European Communities Biomedical Engineering Advisory Committee (COMAC$\mathrm{BME})$ programme of respiratory impedance ( $\mathrm{Zrs}$ ) measurement development [1], and to develop clinical guidelines for $Z$ rs measurement. The present report summarises the most important underlying concepts of the FOT, offers guidelines for its implementation and use in the clinical environment, and gives a brief overview on the latest developments of potential clinical impact.

\section{Methodology}

Since the first FOT measurements by DuBoIs et al. [2], numerous variants of the FOT have been developed in terms of measurement configuration, oscillation frequencies and evaluation principles. This short review is focussed on the routine clinical applications, addressing the most basic concepts only, and the reader is referred for more detailed information to monograph articles [3-7].

\section{Potential and limitations}

The essence of the FOT can be elucidated by contrasting its principle with that of the respiratory mechanical measurements that depend on spontaneous breathing activity or respiratory manoeuvres. Uniquely, for the FOT, external driving signals (i.e. forced oscillations) are used to determine the mechanical response of the respiratory system and the investigator uses specifically developed forcing waveforms to explore the respiratory mechanical properties, relying on the well-developed arsenal of linear system analysis. FOT thus possesses solid theoretical foundations and a high degree of versatility, which are far beyond the capability of conventional respiratory mechanical tests. However, the requirement of linearity necessitates the use of small-amplitude oscillations, which may leave undisclosed some energetically and functionally important nonlinear properties that manifest during tidal breathing, and assumes methodological rigor in both data collection and analysis.

\section{Respiratory impedance}

The key concept of the forced oscillatory respiratory mechanics is the "impedance" $(Z)$, the spectral (frequency domain) relationship between pressure $(P)$ and airflow $\left(V^{\prime}\right)$ (see Appendix). In simple terms, $Z$ can be conceived as a generalisation of resistance, since it embodies both the inphase and out-of-phase relationships between $P$ and $V^{\prime}$. The in-phase component is called the real part of $Z$ (or resistance $(R)$ ), whereas the out-of-phase relationship is expressed by the imaginary part (or reactance $(X)$ ), and both appear as functions of the frequency of oscillation $(f)$. In other words, $R$ describes the dissipative mechanical properties of the respiratory system, whereas $X$ is related to the energy storage capacity and thus determined jointly by the elastic properties (the relationship between $P$ and volume) dominant at low oscillation frequencies and the inertive properties (the relationship between $P$ and volume acceleration), which become progressively more important with increasing $f$.

\section{Measurement arrangements}

Depending on the sites of the $P$ and $V^{\prime}$ measurements and of the application of the forced oscillations, different kinds of impedance of the respiratory system can be defined. Most commonly, the forced oscillations are applied at the airway opening, and the central airflow $\left(V^{\prime}\right.$ ao) is measured with a pneumotachograph attached to the mouthpiece, face mask or endotracheal tube (ETT). Pressure is also sensed at the airway opening $(P \mathrm{ao})$ with reference to body surface (in this case, atmospheric) pressure $(P b s)$. The input impedance of the respiratory system $(Z \mathrm{rs}, \mathrm{in})$ is then the spectral (frequency domain) relationship between transrespiratory pressure $(P$ rs $=P$ ao- $P$ atm $)$ and $V^{\prime}$ ao: $Z$ rs, in $(f)=P$ rs $(f) / V^{\prime}$ ao $(f)$. When $Z$ rs is partitioned into pulmonary $\left(Z_{\mathrm{L}}\right)$ and chest wall impedance $(Z \mathrm{w})$ on the basis of the measurement of intraoesophageal pressure $(P \mathrm{es}), Z \mathrm{~L}$ and $Z \mathrm{w}$ are obtained from $Z \mathrm{~L}=(P$ ao $-P$ es $) /$ $V^{\prime}$ ao and $Z_{\mathrm{w}}=(P$ es $-P \mathrm{bs}) / V^{\prime}$ ao, respectively. A special version of the input FOT is the head generator technique, where $P$ ao is applied around the head, in order to minimise upper airway wall shunting [8]. An alternative instrument that can be used to estimate $Z$ rs, in and that does not require the recording of flow $\left(V^{\prime}\right)$, is a wave tube connecting the source of forced oscillations (usually a loudspeaker) and the subject; $Z$ rs, in is measured as the load impedance on the wave tube, on the basis of the geometric and physical properties of the tube and the inside air, and the pressure recorded at the inlet and outlet of the tube [9]. Transfer impedance is obtained when the oscillations are imposed and $P$ and $V^{\prime}$ are measured at different sites of the respiratory system; accordingly, various measurements of transfer impedance can be instrumented. However, if the impedance of the total respiratory system $(Z \mathrm{rs}, \mathrm{tr})$ is considered, either the oscillatory excitation at the airway opening is combined with the plethysmographic measurement of output, "body surface" flow, or the oscillations are imposed in a "head-out" plethysmograph on the body surface, with the measurement of $V^{\prime}$ ao. As $Z$ rs, in and these two variants of $\mathrm{Zrs}$,tr are affected differently by the parallel elements of the respiratory system, such as alveolar gas compressibility and upper airway wall movements, they can be selected or combined to obtain more reliable estimates of the airway and tissue impedance. The present review is restricted to the most easily implementable FOT, namely $Z$ rs, in.

\section{Oscillation frequencies}

For routine clinical applications of FOT it is usual to apply a medium frequency range, i.e. the imposed oscillations start from 2-4 Hz, roughly 1 decade above the spontaneous breathing rate, and extend up to a few times $10 \mathrm{~Hz}$. In this frequency range, the healthy respiratory system exhibits a largely frequencyindependent respiratory resistance $(R \mathrm{rs})$ whose major component is airway resistance (Raw) (fig. 1). Respiratory reactance $(X \mathrm{rs})$ undergoes the transition from negative values (when the elastic reactance dominates) to positive values increasing with $f$ (the dominance of inertial reactance). At the characteristic resonant frequency ( $f$ res), where $X$ rs crosses zero, the elastic and inertial forces are equal in magnitude and opposite. The low-frequency oscillations include the frequencies of spontaneous breathing and, accordingly, can be applied during apnoeic conditions only, whereas the high-frequency range contains oscillations up to several $100 \mathrm{~Hz}$. Use of lowfrequency and high-frequency forced oscillations reveals different mechanical properties of the respiratory system, and these techniques are promising as lung function test methods; for this reason they are considered in the "New developments" section. The present section of this report focuses on the most commonly used medium-frequency range FOT. 

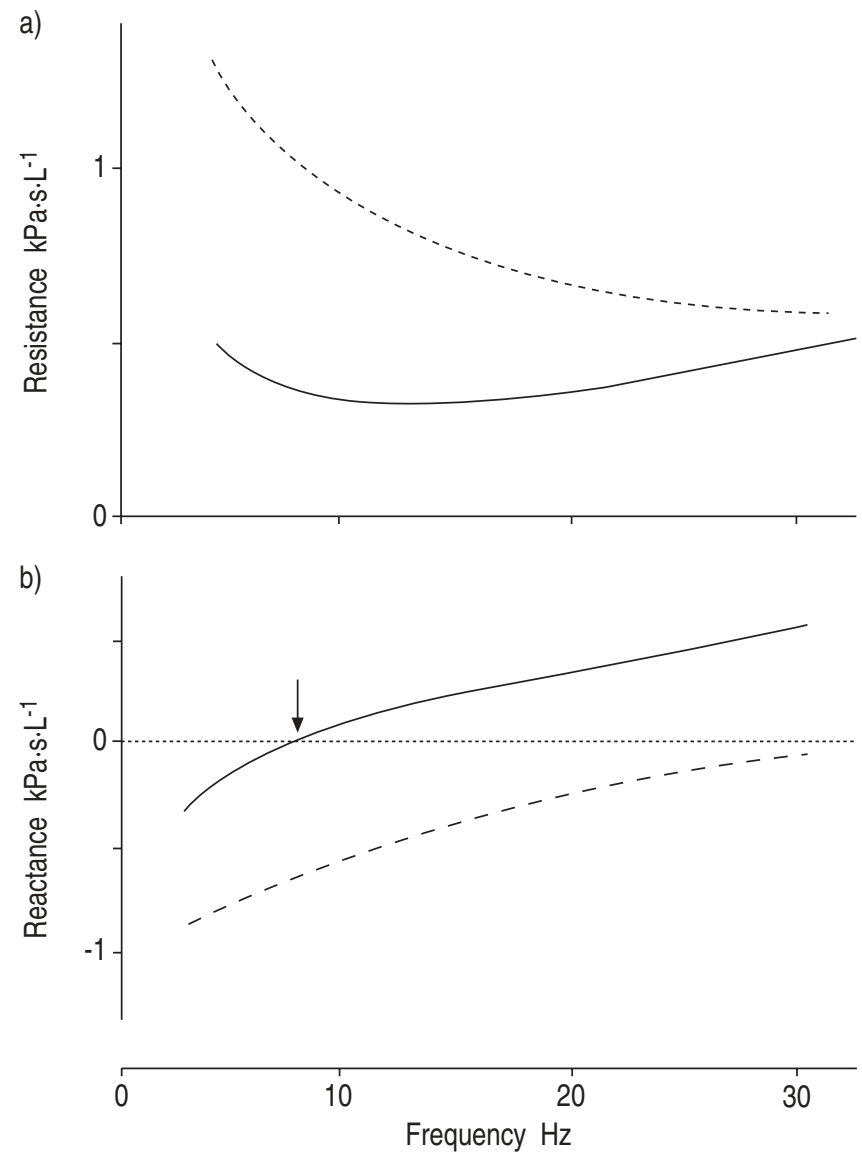

Fig. 1.-Schematic illustration of the frequency dependence of respiratory impedance of adults in the medium frequency range, in health and disease. Compared to the normal impedance data (-), in airway obstruction, respiratory resistance (- - ) is higher (a) and negatively frequency-dependent, whereas respiratory reactance is lower (b). Arrow indicates resonant frequency.

Both single-frequency and composite signals have been used in clinical practice. When the FOT is applied to explore the patterns or mechanisms of frequency dependence of $Z$ rs in health and disease, the simultaneous application of several frequency components, i.e. the use of composite signals, such as pseudorandom noise or recurrent impulses, is preferred. The single-frequency FOT may be used in the tracking of relatively rapid changes in $Z \mathrm{rs}$, e.g. those occurring within the respiratory cycle, or as an accessory device for monitoring airway patency, and it may also be useful in the evaluation of changes in the bronchomotor tone.

\section{Recommendations for measurements}

\section{Set-up}

The subject is connected via a mouthpiece to the set-up that most commonly utilises a loudspeaker to deliver the forced oscillatory signal (fig. 2). The $P$ and $V^{\prime}$ signals are measured next to the mouthpiece. To enable spontaneous breathing of the subject, a shunt pathway open to the atmosphere is necessary; this is usually a wide-bore side tube (with a high impedance to present a small leak for the high oscillatory frequencies and a low resistance against spontaneous breathing) placed in parallel to the loudspeaker. A mechanical resistor may also be used for this purpose. A bias flow to flush

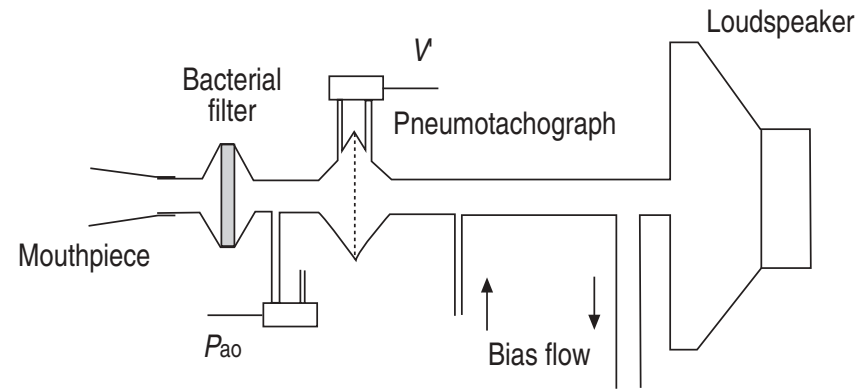

Fig. 2. - Schematic arrangement of the forced oscillatory respiratory impedance $(Z \mathrm{rs}$, in $)$ measurement. $P$ ap: airway opening pressure; $V^{\prime}$ : airflow.

the dead space is optional and can preferably be introduced between the loudspeaker and the pneumotachograph. When a bacterial filter is placed between the set-up and the patient for hygienic purposes, the measured $Z$ rs should be corrected for the impedance of this filter. The dead space of the filter should be minimal to avoid shunting effects at high $Z$ rs.

\section{Apparatus}

The FOT system should impose a load against spontaneous breathing of $<0.1 \mathrm{kPa} \cdot \mathrm{s} \cdot \mathrm{L}^{-1}$ below $5 \mathrm{~Hz}$. When using composite signals, the loudspeaker should be able to develop a peak-topeak pressure variation of $0.2 \mathrm{kPa}$ at the airway opening. The largest $P$ developed in the system should not exceed $0.5 \mathrm{kPa}$.

The differential pressure transducer used for flow measurement together with its connections to the pneumotachograph should be symmetrical and of low compliance, providing a common mode rejection ratio of at least $60 \mathrm{~dB}$ up to the highest frequency investigated [10]. The pressure transducers should have a low sensitivity to accelerations, or at least be protected against vibrations. The flowmeter and the pressure transducer should be linear (within $2 \%$ ) up to at least $1 \mathrm{~L} \cdot \mathrm{s}^{-1}$ and up to $0.5 \mathrm{kPa}$, respectively.

\section{Calibration}

The calibration should take into account the relative static gain and the relative frequency characteristics of $P$ and $V^{\prime}$ measuring devices. To check the overall accuracy of the measurement set-up, the use of a reference impedance, whose theoretical impedance is known from physical principles, is recommended. The magnitude of the impedance of this device should be comparable at all measured frequencies to that of the highest $Z$ rs encountered or expected in the measured subject population, i.e. reference impedance with a magnitude of $\sim 1.5 \mathrm{kPa} \cdot \mathrm{s} \cdot \mathrm{L}^{-1}$ and $\sim 4 \mathrm{kPa} \cdot \mathrm{s} \cdot \mathrm{L}^{-1}$ are suggested for calibration in adult and infant studies, respectively. After proper calibration, a maximum error of $10 \%$ or $0.01 \mathrm{kPa} \cdot \mathrm{s} \cdot \mathrm{L}^{-1}$, whichever is greater, is allowed over the frequency range of interest. Proper calibration and evaluation of the accuracy of FOT set-ups is particularly important since it has been shown that systematic differences in $\mathrm{Zrs}$ were obtained with different devices [11].

\section{Input signals}

It is important to ensure that the test signal is applied for long enough to include several breathing cycles. The amplitude of the signal should be large enough to guarantee a satisfactory signal-to-noise ratio, but not too large so as to avoid discomfort for the subject, nonlinear behaviour of the respiratory system and synchronisation between breathing and 
input signals. A peak-to-peak size of the composite signal of $0.1-0.3 \mathrm{kPa}$ seems optimal [12].

In studies exploring the frequency dependence of $Z \mathrm{rs}$, the use of multifrequency (composite) signals, preferably including the $4-30 \mathrm{~Hz}$ range, is recommended. Usually, the amplitude spectrum of the composite signal is coloured so as to enhance the power at lower test frequencies. This improves the signalto-noise ratio at the lower frequencies that are more contaminated by components of the spontaneous breathing signal. Special procedures have been developed to optimise the composite forcing waveform [13]. Alternatively, when the $Z$ rs data at a single frequency are of interest, a sinusoidal signal at the lowest possible frequency should be used. The lowest frequency at which $Z$ rs can be measured reliably is governed by the relative power of the harmonics of the breathing signal and applied forced oscillation at that frequency.

\section{Signal processing}

Averaging pseudorandom signal epochs by time [14] or the use of the so-called "unbiased estimators" $[15,16]$ reduces the errors introduced at the low frequencies (in adults below $\sim 6 \mathrm{~Hz}$ ) by the higher harmonics of the breathing signal.

The FOT device should be specified according to the data processing technique used in the calculation of $Z$ rs (number and length of time blocks, overlapping, windowing, lowpass and/or highpass filtering, way of calculating coherence function, etc.) [17].

\section{Report of results}

The mean and SD of all Zrs data obtained from successive measurements should be reported. The coefficient of variation (CV) at every measured frequency is the main index of the reliability and repeatability of $Z$ rs data. Reliability indices of the individual measurements, such as the coherence function, are optional to report.

In addition to the $R$ rs and $X$ rs data measured at a given frequency ( $R \mathrm{rsf}, X \mathrm{rsf})$, impedance parameters may be estimated using various model analyses. However, model parameters and curve (polynomial) fittings without raw data are unacceptable.

\section{Measurement conditions}

Subject's position. Measurements are performed in the sitting position with the head in a neutral or slightly extended position. Flexion of the head should be avoided. During the measurement, the subject (or technician) firmly supports his/ her cheeks and the floor of the mouth using both hands and a noseclip is worn. The subject is instructed to breathe quietly at FRC level. When measuring young children, allowing the parents to accompany them in the lung function laboratory improves cooperation. The child should be given some time to adjust to the laboratory environment and trained to breathe quietly through the mouthpiece and to wear the noseclip for a short period of time. The parents can also be given those pieces of equipment to train their child at home should difficulties be encountered.

Volume history. Immediately before the measurement is made, the volume history of the subject should be monitored for at least $30 \mathrm{~s}$. At least $3 \mathrm{~min}$ of quiet breathing should be allowed for recovery if forced respiratory manoeuvres have been made before $Z$ rs is measured.

Measurement acceptance criteria. Swallowing, glottis closure, leak around the mouthpiece, improper seal with the noseclip, irregular breathing or acute hyperventilation during the measurement are reasons to discard the measurement. Most of these events can be detected on the flow signal which should therefore be displayed on the screen during the measurement. If a measurement is considered artefactual, both $R$ rs and $X$ rs should be rejected.

Number of measurements. A total of three to five technically acceptable measurements should be performed. The subject should come off the mouthpiece in between successive measurements in order to establish the short-term variability of $\mathrm{Zrs}$ in a uniform manner. A further indication of baseline variability may be obtained by repeating the baseline measurements 10-20 min later; this is important in the interpretation of bronchomotor tests, particularly when $Z$ rs is the sole index used in evaluating bronchial reactivity. Evaluation of a change in $R$ rs in response to challenge is dependent on the baseline CV value. When baseline reproducibility is poor, further histamine (His) or methacholine (Mch) study is inappropriate both because of difficulty with test interpretation and the risk of underlying poor asthma control.

\section{The upper airway artefact}

With the standard Zrs, in set-up, a component of the measured input flow is lost in the oscillatory motion of the compliant upper airway walls and never enters the lower respiratory system. By the support of the cheeks and mouth floor, it is not possible to eliminate this shunt effect completely [18-20], which increases as $Z$ rs rises. Overall, as upper airway impedance (Zuaw) falls steeply with increasing frequency, upper airway shunting is minimal at low frequencies and becomes increasingly important as oscillation frequency rises. This leads to an artifactual frequency-dependence of $R$ rs and a shift of $X$ rs to higher frequencies (with an increased $f$ res) in children and adults $[19,20]$. The upper airway artefact is particularly important in children for whom Zuaw approximates adult values [21], since $Z_{r s}$ is larger in children and rises progressively with decreasing age.

Several different approaches have been proposed to minimise the effects of the upper airway shunt. One method used to correct for the upper airway shunt by separately determining Zuaw during a Valsalva manoeuvre [18] has been shown to undercorrect $Z$ rs [19, 22], and is also impractical during routine $Z$ rs measurements. Another approach is to apply the oscillating pressure signals around the head and at the mouth (the head generator technique [8]) and this considerably reduces the motion of the cheeks, minimising though slightly overcorrecting for the $Z$ uaw shunt artefact. Compared to the standard method, use of the head generator technique results in $R$ rs values that are larger but less frequency dependent, a steeper increase in $X$ rs with frequency (and therefore lower $f$ res) and larger $R$ rs changes during Mch challenge that are independent of baseline Zrs [19, 23, 24]. By using the change in admittance (the inverse of impedance) instead of $R$ rs to express the response to bronchoprovocation, the result is practically free from the upper airway artefact [25], this way potentially increasing the sensitivity of the conventional set-up.

Studies differ in their assessment of the convenience of the head generator technique. One study suggested that tolerance was poor by some subjects and that data rejection increased at low frequencies $(<10 \mathrm{~Hz})$ [24]. However, in another study satisfactory data could be obtained in all the 380 normal adult subjects but one [26]. In adults, the sensitivity in detecting airway obstruction appeared to be similar with both techniques [24]. In children, the diagnostic value of $R$ rs10 in identifying responses to bronchodilators improved slightly with the head generator compared to the standard method, 
whereas the parameters derived from $X$ rs obtained with the standard method had a better diagnostic value than the head generator technique [27].

In conclusion, with the standard FOT technique, Zrs, especially at higher frequency, is affected by the motion of the upper airway walls. This upper airway shunt results in an artificial frequency dependency of $R \mathrm{rs}$ and $X \mathrm{rs}$ is decreased with increased $f$ res in the presence of a high $Z$ rs. Although elimination of the upper airway shunt during standard $Z$ rs,in measurement is impossible, firm and uniform support of the upper airway walls should be applied. More accurate $Z$ rs data can be obtained using the head generator technique, which minimises the upper airway shunt. However, further studies are needed to identify the improvements offered by this method in terms of its sensitivity and specificity in clinical practice.

\section{Clinical applications}

\section{Reference values}

Adults. A relatively limited number of reference studies of $Z$ rs,in as a function of frequency exist in adult subjects. Healthy subjects exhibit a virtually frequency-independent $R$ rs, with a frequency-dependent $X$ rs usually behaving according to an inertance-compliance system exhibiting an $f$ res $<10 \mathrm{~Hz}$.

An overview of the average $R$ rs values of healthy adult subjects reported from different laboratories is given in table 1. In half of the studies, relatively young subjects (an average age of $<35 \mathrm{yrs}$ ) were investigated; the selection criterion of the subjects was not always reported, or the sample population was limited to a specific subgroup of subjects. Nevertheless, the average $R$ rs of healthy adults varied little among the different studies, and slightly higher $R$ rs values were found for females $\left(0.31 \mathrm{kPa} \cdot \mathrm{s} \cdot \mathrm{L}^{-1}\right)$ compared with males $\left(0.25 \mathrm{kPa} \cdot \mathrm{s} \cdot \mathrm{L}^{-1}\right)$. Prediction equations for the average $R$ rs and $X$ rs, and the slope of the Rrs versus $f$ relationship are given in table 2 [32]. ZERAH et al. [33] analysed $R$ rs data obtained in 40 healthy volunteers by performing linear regression on the data from $4-16 \mathrm{~Hz}$, and back-extrapolating the regression line to $0 \mathrm{~Hz}$ to obtain the parameter $R \mathrm{rs} 0$, and its inverse, respiratory conductance at $0 \mathrm{~Hz}(\mathrm{Grs} 0)$. Grs0 was dependent on height and age but not on sex or body weight.

Children. Normal values have been collected by several research groups [30, 34 45]. An overview of the regression equations of $R$ rs as a function of body height is given in table 3 , and the
Table 2.-Prediction equations for the average resistance $(R \mathrm{rs}(0))$, average reactance $\left(X_{\mathrm{rs}}(0)\right)$ and slope of resistance to frequency $(R \mathrm{rs}(1))$, and the residual SD (RSD)

Male

$\operatorname{Rrs}(0)=-0.2454 . \mathrm{H}+0.001564 . \mathrm{W}-0.00055 . \mathrm{A}+0.5919(\mathrm{RSD}=0.0493)$

$\operatorname{Rrs}(1)=0.00842 . \mathrm{H}-0.000047 . \mathrm{W}-0.000018 . \mathrm{A}-0.0095(\mathrm{RSD}=0.00197)$

$X \mathrm{rs}(0)=0.1479 . \mathrm{H}-0.000402 . \mathrm{W}-0.00022 . \mathrm{A}-0.1721(\mathrm{RSD}=0.0306)$

Female

$\operatorname{Rrs}(0)=-0.4300 . \mathrm{H}+0.00165 . \mathrm{W}-0.00070 . \mathrm{A}+0.9312(\mathrm{RSD}=0.0619)$

$\operatorname{Rrs}(1)=0.01176 . \mathrm{H}-0.000106 . \mathrm{W}-0.000045 . \mathrm{A}-0.00817(\mathrm{RSD}=0.00256)$

$X \mathrm{rs}(0)=0.2487 . \mathrm{H}-0.001700 . \mathrm{W}-0.00053 . \mathrm{A}-0.2158(\mathrm{RSD}=0.0406)$

$\operatorname{Rrs}(0)$ and $X \mathrm{rs}(0)$ in $\mathrm{kPa} \cdot \mathrm{s} \cdot \mathrm{L}^{-1}, \operatorname{Rrs}(1)$ in $\mathrm{kPa} \cdot \mathrm{s}^{2} \cdot \mathrm{L}^{-1}$. $\mathrm{H}$ : height $(\mathrm{m})$; $\mathrm{W}$ : weight $(\mathrm{kg})$; A: age (yrs). Reproduced with permission from [32].

corresponding data are shown in figure 3. Rrs usually falls inversely with height, and, except for one study [34], no sexrelated differences in $R$ rs have been described. In most of these studies, a similar Rrs versus height dependence has been obtained.

The negative frequency-dependence of $R$ rs becomes more pronounced with decreasing age [34-36, 40, 41]. In small children, fres is high (sometimes $>20 \mathrm{~Hz}$ ) and then decreases as $X$ rs becomes less negative with growth. The characteristics of the $X$ rs versus $f$ relationship are significantly modified when a head generator is used to minimise the upper airway wall motion, shifting the curve to the left and reducing fres [20, 46, 47].

Clearly, further large scale studies in adults across a wide age range are needed to validate existing reference values. In children, available regression equations of $R$ rs as a function of body height show a fairly close agreement.

\section{Reproducibility}

The short term intra-individual $\mathrm{CV}$ of FOT indices in healthy adults range $5-15 \%$ (table 4 ), which is comparable to the variability of resistance values obtained with other methods (body plethysmography (sGaw), interrupter technique, etc). For adult patients with airway obstruction the $C V$ values were hardly different from that of healthy subjects.

Similar estimates of short term CV, ranging $<5-14 \%$ have been obtained in children [34, 38, 39, 51, 53-57]. A significant circadian rhythm has been identified in about one-third of an asthmatic children population, although the amplitude of the diurnal variations of $R$ rs did not exceed $20 \%$ [58].

The day-to-day variability has been reported to be slightly larger than the within-day variations in adults, with a CV of 10.0 versus $8.3 \%$ [49] and 10.8 versus $8.6 \%$ [51]. In children,

Table 1.-Overview of the average respiratory resistance $(R \mathrm{rs})$ value obtained in healthy adults.

\begin{tabular}{|c|c|c|c|c|c|c|c|c|}
\hline \multirow[t]{2}{*}{ Reference } & \multirow[t]{2}{*}{ Selection criteria } & \multirow{2}{*}{$\begin{array}{l}\text { Frequency } \\
\text { band } \mathrm{Hz}\end{array}$} & \multicolumn{3}{|c|}{ Male } & \multicolumn{3}{|c|}{ Female } \\
\hline & & & $\operatorname{Rrs~kPa} \cdot \mathrm{s} \cdot \mathrm{L}^{-1}$ & $\mathrm{n}$ & Age yrs & $\operatorname{Rrs~kPa} \cdot \mathrm{s} \cdot \mathrm{L}^{-1}$ & $\mathrm{n}$ & Age yrs \\
\hline$[28]$ & $\begin{array}{l}\text { Male Air Force } \\
\text { members/applicants }\end{array}$ & $4-24$ & $0.25(0.06)$ & 224 & $26(10)$ & & & \\
\hline [29] & $?$ & $8-24$ & $\sim 0.26$ & 442 & 29 & & & \\
\hline [30] & $\begin{array}{l}\text { Patients undergoing } \\
\text { rehabilitation and } \\
\text { healthy hospital workers }\end{array}$ & 10 & $0.29(0.08) \mathrm{M}+\mathrm{F}$ & 102 & 50 & & & \\
\hline [31] & $?$ & $6-24$ & $0.26(0.06)$ & 126 & $33(12)$ & $0.30(0.06)$ & 100 & $29(12)$ \\
\hline [24] & $\begin{array}{l}\text { "Healthy" subjects } \\
\text { referred for lung } \\
\text { function testing }\end{array}$ & $10-32$ & $0.26(0.07)$ & 32 & $48(15)$ & $0.34(0.07)$ & 28 & $55(13)$ \\
\hline [32] & $\begin{array}{l}\text { "Healthy" subjects } \\
\text { referred for lung } \\
\text { function testing }\end{array}$ & $6-24$ & $0.25(0.05)$ & 137 & $53(14)$ & $0.31(0.07)$ & 140 & $58(14)$ \\
\hline
\end{tabular}

Data are presented as mean (SD). M: male; F: female; n: number of subjects studied. 
Table 3. - Overview of the regression equations of respiratory resistance (Rrs) as a function of height in healthy children

\begin{tabular}{|c|c|c|c|c|c|}
\hline Reference & $\begin{array}{c}\text { Frequency } \\
\text { band } \mathrm{Hz}\end{array}$ & $\begin{array}{c}\text { Subjects } \\
\mathrm{n}\end{array}$ & $\begin{array}{l}\text { Age } \\
\text { yrs }\end{array}$ & $R \mathrm{rs} \mathrm{kPa} \cdot \mathrm{s} \cdot \mathrm{L}^{-1}$ & RSD \\
\hline [42] & $15-35$ & 16 & $3-5$ & $\operatorname{Rrs}(15-35)=-0.00529 \times \mathrm{H}+1.102$ & \\
\hline [41] & 4,9 & 130 & $3-14$ & $R \mathrm{rs} 4=2.47-0.013 \times \mathrm{H}$ & \\
\hline [36] & $3-10$ & 121 & $4-16$ & $R \mathrm{rs} 4=1.87 \times 10^{4} \times \mathrm{H}^{-2.12}$ & \\
\hline [38] & $2-26$ & 138 & $2-16$ & $R \mathrm{rs} 6=9.2 \times 10^{-5} \times \mathrm{H}^{2}-0.0341 \times \mathrm{H}+3.52$ & 0.15 \\
\hline$[40]$ & $2,4,12$ & 218 & $2-18$ & $\log (\operatorname{Rrs} 4)=4.413-2.18 \times \log (\mathrm{H})$ & $10.2 \%$ \\
\hline [34] & $2-26$ & 255 & $2-12$ & $R_{\mathrm{rs} 6}=0.00017 \times \mathrm{H}^{2}-0.05407 \times \mathrm{H}+4.77323$ & 0.175 \\
\hline [39] & 10 & 377 & $3-18$ & $\operatorname{Rrs} 10=1.392-0.00635 \times \mathrm{H}$ & 0.066 \\
\hline [44] & 5 & 247 & $3-6.5$ & $R \mathrm{rs} 5=-0.009528 \times \mathrm{H}+2.0643065$ & \\
\hline [45] & $8,12,16$ & 199 & $3-17$ & $\ln (R \operatorname{rs} 8)=10.990-2.370 \times \ln (\mathrm{H})$ & \\
\hline
\end{tabular}

H: height (cm); RSD: residual SD.

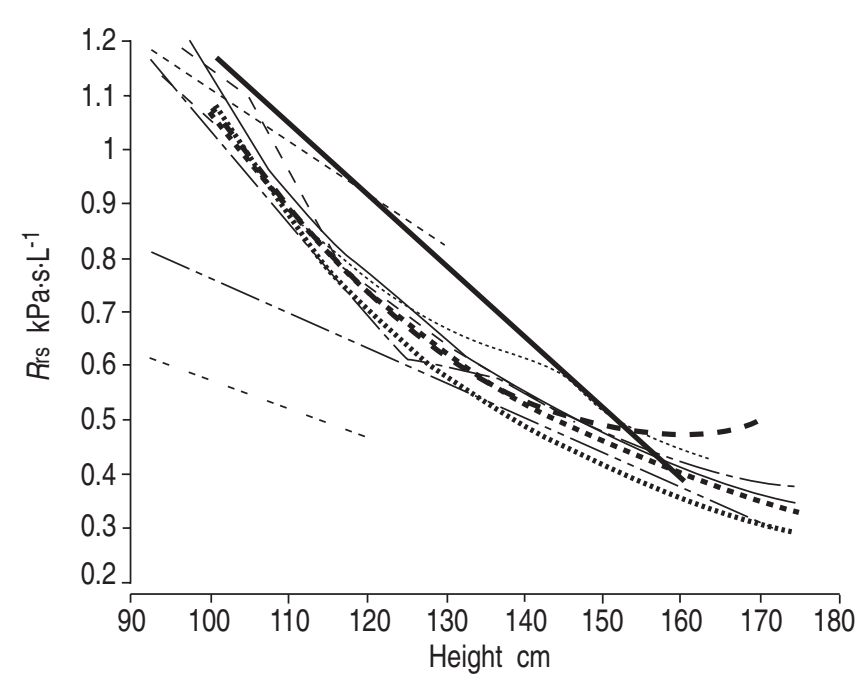

Fig. 3. - Regression curves or mean values of respiratory resistance (Rrs) versus height in different studies. - : [40]; - - : [37]; - - - : [36]; ….....: [35]; - : [41]; - - - : [44]; - - - : [38]; - - - : : [39]; -- -.- --: $[42] ; \cdots:[34] ; \ldots \ldots \ldots:[45]$.

the day-to-day $\mathrm{CV}$ and the weekly variability were found to be $16 \%[54]$ and $17 \%[34]$.

\section{Diagnostic capacity}

Whereas the difference in Zrs parameters between subjects with normal and abnormal spirometry has been repeatedly

Table 4. - Short term (within day) intra-individual variability of forced oscillation technique (FOT) indices in adult, healthy subjects and patients

\begin{tabular}{|c|c|c|c|}
\hline Reference & FOT index & Subjects studied & $\mathrm{CV} \%$ \\
\hline \multirow[t]{2}{*}{ [48] } & $\operatorname{Rrs} 10$ & Healthy subjects & 11.3 \\
\hline & & Asthmatics & 10.3 \\
\hline \multirow[t]{2}{*}{ [49] } & Rrs8 & Healthy subjects & 8.3 \\
\hline & & Asthmatics & 10.0 \\
\hline [50] & $|Z \mathrm{rs} 10|$ & Asthmatics & 4.9 \\
\hline [12] & $R \mathrm{rs} 4-32$ & Healthy subjects & 4.7 \\
\hline [30] & $\operatorname{Rrs} 10$ & Healthy subjects & 9.8 \\
\hline \multirow[t]{2}{*}{ [51] } & $\operatorname{Rrs} 10$ & Healthy subjects & 8.6 \\
\hline & & COPD patients & 8.8 \\
\hline [52] & Rrs6 & Patients with airway obstruction & 15.2 \\
\hline [52] & Rrs6-26 & Patients with airway obstruction & 12.1 \\
\hline
\end{tabular}

Rrs6, Rrs8, Rrs10: Rrs measured at 6,8 or $10 \mathrm{~Hz}$; $|Z \mathrm{rs} 10|:$ modulus at $10 \mathrm{~Hz}$; CV: coefficient of variation. pointed out, there is currently no recognised FOT index of airway obstruction. Interpretation of $R$ rs deviations from normal inpatients and pathological conditions should take into account the wide scatter of Rrs values among normal individuals. To this end, the difference between observed and predicted Rrs may be divided by the SD of the corresponding reference population. This ratio will be referred to as the SD index.

Adults. The pattern of change in $Z$ rs in various pulmonary function abnormalities consists of an increase in $R$ rs, especially in the lower frequency range, and a decrease in $X \mathrm{rs}$, associated with an increase in fres. CLÉMENT et al. [29] demonstrated that conventional FOT was a sensitive tool to separate healthy subjects from patients with respiratory complaints (both with and without a reduced forced expiratory volume in one second (FEV1)). In a later study, the same investigators showed that the sensitivity to detect symptomatic people was similar for FOT and spirometry [32].

In adult patients with intrapulmonary airway obstruction, $R$ rs is increased at the lower frequencies and falls with increasing $f$. The negative frequency-dependence of $R$ rs is explained on the basis of mechanical inhomogeneities of the lungs [2]. VAN NOORD et al. [59] studied the discriminative power of conventional lung function parameters and FOT in three groups of patients suffering from asthma, chronic bronchitis or emphysema with a similar reduction in FEV1. A discriminant analysis showed that the FOT parameters were among the best lung function indices in discriminating between the three groups; Rrs was highest in asthmatics and the frequency dependence of $R$ rs and decrease in $X$ rs were lowest in emphysema. In early emphysema, patients may present with normal values of $R$ rs and $X$ rs [60]. Wesseling and Wouters [61] found abnormal $\mathrm{Zrs}$ data in $70 \%$ of the subjects with chronic bronchitis in the presence of normal spirometry.

The negative frequency dependence of Rrs, which is characteristic of patients with bronchial obstruction, has also been observed in adult patients with upper airway obstruction but without any sign of intrapulmonary disease [62]. This finding can readily be explained by the shunt effect of the upper airway walls on the elevated distal impedance. Although the FOT may fail in distinguishing between intra and extrapulmonary obstruction, it may be very useful for the noninvasive diagnosis and follow-up of patients at risk for tracheostenosis [63]. In this recent study, FOT indices proved to be much more closely related to the tracheal dimensions than spirometric indices, thus suggesting that FOT is more sensitive in disclosing the upper airway stenosis.

Surprisingly, no distinctive patterns in $\mathrm{Zrs}$ have been observed in restrictive lung disorders: the changes in $\mathrm{Zrs}$ are similar to those of moderate obstructive lung disease. Greater negative frequency dependence and higher values of $R$ rs and decreases in $X$ rs were measured in patients with restrictive disorders, 
such as fibrosing alveolitis [64] and kyphoscoliosis or ankylosing spondylitis [62]. Again, this observation can be explained on the basis of the upper airway shunt impedance, which may mask the differences between the alterations in pulmonary mechanics resulting from various respiratory disorders. Further studies employing the head generator technique are necessary to confirm this assumption. Obese subjects exhibit an increased $R$ rs resulting from a reduction in lung volume [65].

In conclusion, in patients with various diseases associated with pulmonary function abnormalities, an increase in Rrs, especially in the lower frequency range, and a decrease in $X$ rs with a concomitant increase in fres, are observed. However, the standard FOT does not offer the distinction between the underlying restrictive and obstructive changes, or intra and extrapulmonary disorders.

Children. Stable asthma. Most FOT studies in well characterised paediatric asthma deal with children in a stable condition who undergo provocation tests (see below), and relatively few data are available regarding the assessment of baseline airway obstruction. In an early study by CoGSwELL [37] 23 of 42 asthmatic children showed an Rrs5 SD index $>2$. LEBECQUE and STANESCU [66] found that Rrs10 provided information concordant with FEV1 in most asthmatic children. HoLMGREN et al. [67] observed a larger baseline Rrs4 SD index in asthmatic children compared with healthy controls, in keeping with the FEV1 SD index. In a large population of children with various respiratory conditions, including chronic cough and asthma, Rrs was characterised by the extrapolated $R \mathrm{rs} 0$ value [57]. The SD index of $R \mathrm{rs} 0$ was significantly larger in children with abnormal FEV1 than in those with normal FEV1 and, within the latter population, significantly different between the children with normal and those with abnormal midexpiratory flow.

Rrs measured by the FOT in the lower range of the frequency spectrum is significantly different between healthy and asthmatic children, and it distinguishes between the asthmatics with and without abnormal spirometry. Further research is needed to establish a practical FOT index to define airway obstruction on a routine basis.

Acute asthma. A recent study evaluated the feasibility of FOT in an emergency department, assessing 150 children (age 2-17 yrs) [68]. One-quarter of the subjects (median age 3 yrs) were unable to breathe steadily via the measuring device. The success rate for achieving reproducible measurements increased from $0 \%$ (at age 2 yrs) to $83 \%$ (at age $5 \mathrm{yrs}$ ), respectively. Across all ages, the ability to cooperate with spirometry and its reproducibility was similarly poor. Rrs8 $\%$ pred was found to correlate with clinical asthma severity [68]. A further emergency room study in preschoolchildren revealed how $R$ rs 8 related only marginally to asthma severity ratings, but showed that significant correlations between these two rating methods were present when assessing responses to treatment [69].

In acute asthma, FOT measurements may prove useful for objectively assessing bronchodilator responses and to a lesser extent in scoring asthma severity. Limitations of FOT in preschoolchildren include lack of cooperation, poor tolerance of the dead space of the test instrument, poor signal-to-noise ratios due the more rapid respiratory rate, and impaired discriminative power, due to the increased influence of the upper airway wall compliance. Methodological improvements in FOT may ameliorate some of these factors.

Cystic fibrosis. In children with cystic fibrosis (CF), Zrs exhibits a generally poor relationship to the conventional spirometric indices $[37,66,70,71]$. Specifically, FEV1 correlated poorly to Rrs10 [66] and Rrs6 [71], in sharp contrast to the good agreement observed in asthmatics [66]. As the relationship between spirometry and plethysmographic Raw was similarly poor, this problem is unlikely to be unique to FOT. In $\mathrm{CF}$ patients who demonstrated paradoxical response to a bronchodilator, the decrease in FEV1 induced by salbutamol was not paralleled by an increase in Rrs6 [71]. From this, salbutamol was postulated to relieve bronchoconstriction and increase airway wall compliance. Consequently, Rrs was decreased during tidal breathing but flow limitation during forced expiration was facilitated [71].

The discrepant information between FOT and spirometry in CF patients may reflect alterations in the elastic properties of the bronchial wall. Whatever the mechanisms, the routine assessment of lung function in these children should be interpreted with much caution, when either spirometry or FOT is available alone. Further comparative assessments are indicated to clarify the mechanisms of impairment in respiratory function in $\mathrm{CF}$.

Chronic lung disease of prematurity. In a small population of children with a history of premature birth and chronic lung disease studied at a mean age of $6 \mathrm{yrs}$, the values of Rrs6 were weakly related to the clinical history, whereas the frequency dependence of $R$ rs was a more sensitive index in discriminating between children with and without chronic lung disease [72]. At a mean age of 8 yrs, significant alterations in $R$ rs5 and $X$ rs5 were observed in subjects with chronic lung disease as compared with the healthy controls. Furthermore, $X \mathrm{rs} 5$ and $f$ res both differentiated between the presence and absence of chronic disease in premature infants [73]. In the same study, Xrs5 and Rrs5 also showed significant correlations with FEV1. A good agreement between $R$ rs5 and plethysmographic Raw was reported up to $1 \mathrm{kPa} \cdot \mathrm{s} \cdot \mathrm{L}^{-1}$, while the relationship plateaued at higher values of Raw [73], possibly because of the increased impact of the upper airway artefact [23].

In conclusion, abnormal $R$ rs and $X$ rs may be found at school age in children with a history of premature birth and chronic lung disease. However, more studies are needed to characterise the changes in $Z$ rs during growth in these children.

\section{Follow-up and field studies}

In evaluating the development of pulmonary disease, the long-term monitoring of therapeutic efficiency and the staging of respiratory function decline during aging, FOT provides a convenient follow-up technique [74]. However, for longitudinal follow-up of chronic obstructive pulmonary disease (COPD) patients, changes in Rrs up to $26 \%$ may result from spontaneous variation in resistance [51].

Smoking. In an early study, use of FOT alone failed to clearly separate smokers from nonsmokers [28]. COE et al. [75] analysed $R$ rs and its frequency dependence in healthy neversmokers and in smokers. There was a strong trend for $R$ rs (especially at lower frequencies) and the frequency dependence of $R$ rs to elevate with increasing age in the smokers. Increases in $R$ rs and the frequency dependence of $R$ rs were usually present when spirometry indicated bronchial obstruction. The frequency dependence of $R$ rs proved even somewhat more sensitive than spirometry in the detection of mild airway disease.

The frequency dependence of Rrs and its change between air and helium $(\mathrm{He}) /$ oxygen $\left(\mathrm{O}_{2}\right)$ breathing were shown to be more sensitive than the results of spirometry in the detection of early airway abnormalities associated with smoking history and occupational exposure [76]. A study on the additional 
effects of smoking habits on the activity of miners showed that, although FOT provided sensitive indices of the effect of occupational exposure on central airways, it did not detect the additional effect of smoking [77].

Epidemiological surveys and field studies. The information offered by FOT on respiratory impairment is in every way as significant as spirometry and FOT does not require active cooperation. Feasibility in various epidemiological surveys and field studies has been excellent [78]. Both the standard and head generator methods exhibit comparable potential to classify a variety of respiratory status measures amongst agricultural workers (smoking status, cough, expectoration and airway obstruction assessed by maximum expiratory flow/volume curve) [79].

FOT has proved as sensitive as spirometry in the detection of impairment in ventilatory function in workers exposed to occupational dangers [80, 81].

The performance of FOT in the assessment of bronchial hyperresponsiveness (BHR), as compared with spirometry was studied in 119 active workers with normal baseline pulmonary function [81]. When a $65 \%$ increase in $R \operatorname{rs} 0$ was used to classify the subjects according to the presence or absence of a $20 \%$ fall in FEV1, FOT reached a sensitivity of $75 \%$ and a specificity of $76 \%$. Using a simplified FOT index, the two-point dose response slope of the change in Rrs10, BOHADANA et al. [82] established a sensitivity of $91 \%$ and a specificity of $96 \%$ in the accurate detection of "spirometric" BHR in various patients referred for BHR testing. This suggests that this simple index can be used for BHR testing in occupational epidemiology.

In sickle cell disease, an increase in $R$ rs is correlated with the number of acute chest syndrome episodes, which demonstrates that obstructive lung dysfunction is fairly common in this type of disease [83].

In a survey of respiratory health involving $>1,500$ children aged 6-12 yrs, measurements of $Z$ rs failed to differentiate symptom-free children from those with a history of chronic cough or asthma-like symptoms in the previous year [35]. This was thought to reflect either the poor diagnostic value of the technique or the lack of functional abnormality associated with such a history of respiratory symptoms.

In conclusion FOT has proven to be at least as sensitive as spirometry to detect impairment of lung function due to exposure to cigarette smoke or occupational hazards. The sensitivity to detect mild airway disease and the minimal requirements for subject's cooperation make FOT a very suitable lung function test for epidemiological and field studies.

\section{Identification of airway reactivity}

The interpretation of changes in a lung function parameter measured in response to bronchomotor agents must rely on an estimate of the variability of that parameter. For instance, a response larger than twice the average baseline $\mathrm{CV}$ is usually considered positive. The magnitude of the change induced by bronchodilating or bronchoconstricting agents can also be expressed as the difference between postbronchodilator (or challenge) $R$ rs and $R$ rs at baseline divided by the (average intrasubject) SD of the baseline measurements. This ratio will be referred to as the SD score.

\section{Reversibility}

Adults. The first reports on the changes in $Z_{\text {rs }}$ in response to bronchodilation in COPD patients were based on measurements made in a very limited number of patients [18, 84].
Overall, Rrs decreases after bronchodilation, especially at low frequencies. This reduces the negative frequency dependence of $R \mathrm{rs}$, and, by increasing $X \mathrm{rs}, f$ res returns towards lower and more normal values. Studying $Z$ rs changes in COPD patients, WouTERs et al. [85] noted that only $X$ rs data showed significant changes, whereas low-frequency data suffered from poor coherence. In a large group of patients with airway obstruction (presumably mainly COPD patients), VAN NoORD et al. [52] observed significant postdilator falls in $R \mathrm{rs}$, with a significant correlation between FEV1 and Rrs6. In this study, a threshold value for significant bronchodilation was defined from the within-subject variability of the different lung function indices, a decrease of $>45 \%$ in $R$ rs 6 from baseline value. Here, FOT indices were markedly less sensitive than body plethysmographic or spirometric indices for detecting significant bronchodilation. By contrast, ZERAH et al. [33], who studied the reversibility of airway obstruction in two small yet well-defined groups of patients with asthma and COPD, came to precisely the opposite conclusion. Employing a threshold value of $10 \%$ predicted for both indices, the changes in FEV1 and Grs0 after bronchodilator inhalation were compared. FEV1 and Grs0 both exhibited comparable changes with a similar sensitivity and specificity to differentiate asthmatics from COPD patients. These authors concluded that FOT can be used as an alternative, equivalent technique to forced expiration to assess the degree of bronchodilation.

It is obvious that the correlation between the changes in FEV1 and those in $Z$ rs indices strengthens with increasing response to bronchodilation. Therefore, the correlation between spirometry and $\mathrm{Zrs}$ is dependent on the population studied (asthmatics versus COPD patients).

To summarise, there is no consensus regarding the sensitivity of $Z$ rs measurement compared with that of spirometry and the correlation between their indices in bronchodilation testing. Further research in larger, well-defined groups is needed to establish whether FOT and spirometry are equivalent or complementary lung function techniques in the assessment of reversibility of airway obstruction.

Children. Indirect evidence of airway obstruction associated with asthma may be provided by a positive response to a bronchodilator. In a large population of children with chronic respiratory symptoms, the best cut-off value to establish significant reversibility in response to salbutamol with reference to an increase in FEV1 $\geqslant 10 \%$ pred was a decrease in $R$ rs0 of $\geqslant-1$ SD score, or equivalently a $27.8 \%$ decrease in $R \operatorname{rs} 0$ [57]. This cut-off value was associated with a sensitivity and specificity of $69 \%$ and $78 \%$, respectively. In addition, in children unable to perform forced expiration manoeuvres, the cut-off value identified a subgroup of patients whose high baseline $R \mathrm{rs} 0$ normalised after bronchodilator inhalation [57]. In a study of asthmatic children, inhalation of salbutamol induced a decrease in Rrs10 from $155-99 \%$ pred, which corresponded to an increase in FEV1 from $65-85 \%$ pred [66]. In children treated for acute asthma in a paediatric emergency department, the decrease in Rrs8 after salbutamol was found to correlate with the reduction of signs of respiratory distress and the improvement in FEV1. In those children unable to perform spirometric manoeuvres, the reduction in Rrs8 after salbutamol was also associated with a clinical response, and the optimal change in $R r s 8$ to assess reversibility was $19 \%$ [86]. Below aged 7 yrs, considerable overlap exists in bronchodilator response between healthy and asthmatic children. An average decrease of $12 \%$ in Rrs 5 was observed in the healthy children; to exceed the $95 \%$ confidence interval for bronchodilator response in healthy children, a cut-off value of a $41 \%$ decrease in Rrs5 should be used to support the diagnosis of asthma in reversibility testing [44]. In young children, FOT has been 
shown to provide a useful and objective method to assess airway responses to bronchodilator drugs, such as metaproterenol, ipratropium bromide or salbutamol versus placebo [87-90], and to characterise dose/response curves [88, 91]. For example, the bronchodilating effect of nebulised oxitropium bromide (750 and $1500 \mu \mathrm{g})$ in preschool asthmatic children was shown to last for up to $4 \mathrm{~h}$ postinhalation, whereas no additive bronchodilation by fenoterol could be shown [92] .

When defining reversibility of airway obstruction, the FOT criterion should take into account the "normal" physiological response to inhaled $\beta_{2}$ agonist. This has been reported to be a $12 \%$ decrease from the baseline value for $R$ rs in young children. Using comparison with spirometry, the optimum definition of significant bronchodilation has been defined as a decrease in $R$ rs of $\geqslant 1$ SD score. However, more research is needed in well-defined and different age groups of children to confirm that this cut-off level is appropriate.

\section{Bronchial hyperresponsiveness}

The degree of airway responsiveness is commonly assessed with a bronchial challenge test where His, or Mch, is administered in increasing doses until either a bronchoconstriction is observed or a preset maximum concentration has been reached. Clinical methodology for BHR testing has been standardised and the result of the test is expressed as the provocative dose (PD) or concentration (PC), which induces a predetermined deterioration of lung function, usually defined as a decrease in FEV1 of $20 \%$ of the baseline value, noted as the PD20FEV1 or PC20FEV1 [93, 94]. In terms of FOT parameters, the dose of the bronchoconstrictor agent that produces a $50 \%$ increase in Rrs, or equivalently a $33 \%$ decrease in Grs, will be noted as PD50Rrs or PD33Grs.

Adults. A significant correlation between the changes in Rrs and FEV1 following bronchoconstriction has been reported by several investigators [50, 81, 95-97]. SNASHALL et al. [50] compared FEV1 to the modulus of $Z$ rs at $10 \mathrm{~Hz}(|Z \mathrm{rs} 10|)$ in the assessment of BHR in 24 asthmatic patients; the increase in $\mid Z$ rs10| after challenge was on average 2.7 times as much as the decrease in FEV1. Based on the average within-subject CV, they argued that PC30|Zrs10| was equivalent to PC20FEV1. In all but one patient, $\mathrm{PC} 20 \mathrm{FEV} 1$ was larger than $\mathrm{PC} 30|\mathrm{Zrs} 10|$, and in six patients PC20FEV1 was more than two doubling doses of $\mathrm{PC} 30|Z \mathrm{rs} 10|$. In another study, PC20FEV1 was compared with PC40Rrs8 when analysing the response to His and Mch challenge in 23 stable asthmatics [97]. For both agents, PC40Rrs8 was about three times lower than PC20FEV1. Using the same argument on the average within-subject $\mathrm{CV}$, BOHADANA et al. [82] compared PD47Rrs10 (and PD47Rrsmean) to PD20FEV1 in assessing BHR to carbachol challenge. However, by using this cut-off value, far more patients were classified as positive responders than based on FEV1 (for $R$ rsmean and $R$ rs10, 58 and 52 positive responders of the 71 tested patients, respectively, compared to the 23 positive responders for FEV1). In volunteers subjected to His challenge, NeILD et al. [48] showed that PD35Rrs10 was comparable to PD10FEV1, and, consequently, lower than PD20FEV1. The repeatability of $\mathrm{PD} 35$ Rrs10 was slightly lower than that of PD10FEV1. VAN NoORd et al. [98] compared PD15FEV1, PD47Grs6 and PD40sGaw in analysing the response to His challenge in 53 subjects with a history of episodic wheezing. The parameters with the best sensitivity to detect the effect of His were, in decreasing order, sGaw, Grs6 and FEV1; their results also suggested that the sensitivity of Grs6 was larger than that of FEV1 in subjects with a more pronounced bronchial hyperreactivity. FOT was also compared with spirometry in the assessment of BHR in an active working population [81]; the best cut-off point was an increase of $65 \%$ in $R \mathrm{rs} 0$, which reached a sensitivity of $75 \%$ and a specificity of $76 \%$ with PD20FEV1 as the gold standard for classification of the subjects. SCHMEKEL and SMITH [99] used inhalation of cold air as a bronchial challenge test in both asthmatics and healthy controls. Their results indicated that FOT was more able to discriminate between the two groups than spirometry, when using the clinical diagnosis as the gold standard. fres had the highest specificity (100\%) and sensitivity (89\%), and even Rrs5 had a higher diagnostic capacity than FEV1 (specificity and sensitivity of $89 \%$ and $88 \%$, and $88 \%$ and $73 \%$ for $\operatorname{Rrs} 5$ and FEV1, respectively). CHINET et al. [100] compared FOT (Grs0) with $\mathrm{s} G$ aw in providing information on bronchial sensitivity. They found a close relationship between Grs0 and sGaw in terms of threshold dose and the slope of the dose/response curves in normal and hyperresponsive subjects, with equivalence between PD50sGaw and PD42Grs0.

The deep inspiration that precedes forced expiration may modify airway smooth muscle tone, and, therefore, may influence the result of the BHR test. FOT has the considerable advantage that it measures airway properties during quiet breathing. This may be the reason why FOT has proved more sensitive than FEV1 to detect changes in BHR in asthmatics after corticosteroid treatment [101].

FOT has been used to study the site of airway obstruction during induced bronchoconstriction in normal subjects [102, 103] and in asthmatics [104], to evaluate the response to inhaled allergen in asthmatics [96], to examine the effect of posture [105] and hypoxia on BHR [106] and to investigate the ventilatory pattern after induced bronchoconstriction in asthmatics and normal subjects [107].

In conclusion, the values of Rrs (or Grs) at low frequency have been shown to be reliable and sensitive indices to assess the bronchial response in clinical BHR testing. There is evidence that FOT and plethysmography provide comparable information on bronchial sensitivity and responsiveness and may be superior to spirometry. It is not yet clear which cut-off value for $R$ rs corresponds best to the $20 \%$ decrease in FEV1. Threshold values up to the $47 \%$ increase in $R$ rs have been associated with lower PD, or a higher number of positive responders than in the case of PD20FEV1; other studies estimate this threshold value between $65-90 \%$ increase in Rrs.

Children. The Mch or His dose/response curves have usually been characterised by the values of PD40Rrs or PD50Rrs. Most of the meaningful FOT data have been obtained at low frequency. A better sensitivity to detect a bronchial reaction to allergen challenge was reported for Rrs4 (determined using sinusoidal excitation) than for FEV1 in asthmatic schoolchildren aged 6-14 yrs [53]. Significant linear relationships between changes in FEV1 and Rrs indices were observed by DUIVERMAN et al. [108] and LEBECQUe et al. [109] during Mch and His provocation, respectively. In 20 asthmatic children aged 9-16 yrs, the PD40Rrs6 was found to correlate well with PD20FEV1 [108]. A close relationship was found between the effect of His and of Mch in asthmatic children, aged 3-7 yrs, as determined with FOT [110]. The sensitivity of $Z$ rs values to carbachol challenge in children aged 5-16 yrs was found equivalent to that of specific airway resistance (sRaw) [55]. In a population of asthmatics aged 8-15 yrs, the response to His was similarly estimated by transcutaneously determined $\mathrm{PO}_{2}$ $\left(P \mathrm{tcO}_{2}\right)$ and $\mathrm{Rrs} 4$, and PD50Rrs4 was inversely correlated to the clinical severity of asthma [67]. By contrast, in a detailed study in children aged 5 yrs, comparing the Mch-induced changes in $Z$ rs, in and $\mathrm{PtcO}_{2}$, a low diagnostic power for Rrs6 and Rrs8 was observed [111]. FOT has been evaluated in young asthmatics for the detection of the response to Mch in comparison with 
$\mathrm{PtcO}_{2}$, sRaw and the Rrs measured by the interrupter technique (Rrs,int). The sensitivity was lower for $X \mathrm{rs} 5$ than for sRaw, but larger than for $\mathrm{PtcO}_{2}, R \mathrm{rs}_{5}$ or $R \mathrm{rs}$, int in the children aged 2-4 yrs [112]. In the asthmatics aged 4-6 yrs, a better sensitivity in detecting the Mch response was observed for $R$ rs5 and $X$ rs5 than for $\mathrm{s}$ Raw, $\mathrm{PtcO}_{2}, R \mathrm{rs}$, int and FEV1, whereas the higherfrequency values of $R$ rs and $X$ rs were apparently not associated with a good diagnostic score [113].

In the pattern of impedance change after provocation, the increase in $R$ rs was accompanied by a decrease in $X$ rs in most of the studies. Since the apparent elastic properties of the respiratory system as reflected by $X$ rs at lower frequencies $[112,114]$, appear as a sensitive measure in the provocation tests, the variations of the $X$ rs values should be documented.

FOT measurements have shown to reliably reflect the changes in lung function during bronchial challenge in children, with sensitivity comparable to that of bodyplethysmography and spirometry. PD50Rrs is closely related to PD20FEV1. There are indications that $X$ rs may be more sensitive than $R$ rs to detect the response to bronchial challenge, especially in the very young child, but more research is needed to establish the place of $X$ rs in the evaluation of BHR. Additionally, it is recommended that measurement of $Z \mathrm{rs}$ is associated with the careful clinical evaluation, which includes monitoring of transcutaneous $\mathrm{sO}_{2}$ during bronchial challenge. These aspects are important because of the lack of criteria to define airway obstruction in the baseline condition, especially in the young child.

\section{Forced oscillation technique in infancy}

Like other pulmonary function tests in this age group, poor cooperation means that $Z$ rs must be measured during sedation and that testing can be lengthy and technically extremely demanding. For this reason, collection of normal Zrs data in infants has been hampered, as have routine applications of FOT in this subject group.

Standardisation of the measurement conditions for lung function testing is a crucial issue for the infant's safety and the accuracy of the test. Recommendations have been developed by an American Thoracic Society/European Respiratory Society Working Party [115] and the specific preparation measures for the FOT and details of the methodology have been described by DESAGER et al. [116]. The large values of $Z$ rs in infants impose particularly strict performance requirements concerning the measurement set-up and the calibration procedure [117-119].

Most studies in infants deal with validation of the technique. The measurements of $Z$ rs have shown to be reproducible with an average difference in $R$ rs from measurements made 15 min apart of $0.5 \pm 5.7 \%$ [118], and a reasonably good correlation has been reported between the results of FOT and those of the single-breath occlusion method [120]. The impact of the upper airway wall shunt [121, 122] and the nasal breathing [123] on $Z$ rs has been evaluated. The nasal $Z$ was shown to correlate with the clinical observation of nasal obstruction [123]. The feasibility of the FOT during artificial ventilation has been demonstrated in infants with bronchiolitis [124] and FOT has proved to be helpful in titrating optimal positive end-expiratory pressure [125]. In a prospective cohort study, low values of Grs6 measured during the neonatal period were reported to represent a significant risk factor for the occurrence of wheezing later in infancy [126]. FOT combined with FRC measurements detected lung function abnormalities in a minority of wheezing infants during a symptom-free interval [127]. Supporting previously clinical observations, the characteristic bronchodilator effects of nebulised salbutamol, phenylefrine, fenoterol and ipratropium bromide were confirmed using FOT [128]. No clinical or bronchodilating effect of furosemide was observed in intermittently infant wheezers [129]. Recently, methodological and clinical feasibility studies have employed special low and high-frequency test signals and these are addressed in the next section.

\section{New developments}

\section{Applications of forced oscillation technique in monitoring respiratory mechanics}

The FOT has recently been applied to follow the changes in respiratory mechanics during conventional mechanical ventilation (CMV), respiratory manoeuvres and sleep studies. Monitoring of $Z$ rs may be a useful complementary tool in the adaptation of ventilator settings during invasive and noninvasive ventilation [130-135]. The FOT has also been used to improve the diagnosis of sleep disturbances [136] and to determine the optimal continuous positive airway pressure (CPAP) level required to treat obstructive sleep apnoea [137-140]. In sleep studies, changes of Zrs along the breathing cycle are followed, since obstructive sleep apnoeas/hypopnoeas are characterised by marked changes within the breathing cycle [138]. Separate analysis of inspiratory and expiratory impedance has also been suggested in the monitoring of the mechanically ventilated patients [130]. Single-frequency FOT has recently been proved an ideal tool to track $R$ rs or pulmonary resistance during a respiratory manoeuvre including a deep inhalation [141, 142], since it offers a good temporal resolution and the small amplitude oscillations do not interfere with the mechanical changes evoked by the manoeuvre.

The application of FOT in patients subjected to positive pressure requires a modification of the conventional FOT system based on a loudspeaker. Different approaches have been proposed to apply forced oscillations at elevated airway pressure $[130,133,138,143-145]$. If the oscillations are applied through a nasal/face mask or ETT, further technical problems need to be taken into consideration. First, imperfect sealing around the mask or the ETT can cause air leaks, so providing a shunt pathway that leads to a misestimation of $Z$ rs. Secondly, when using a full face mask in which the patient can breathe freely through the nose or the mouth, the actual route of breathing must be known, since the nasal impedance constitutes a significant fraction of $Z_{\text {rs }}$ [133]. Thirdly, for intubated patients, the high impedance and nonlinear behaviour of the ETT pose a further problem, which can be circumvented by measuring the tracheal pressure [146]. An alternative approach is to correct the $Z$ rs values for the effective impedance of the ETT [130] estimated in vitro using similar flow conditions to those of in vivo measurements.

\section{Low-frequency oscillations}

If the oscillatory signal is superimposed on spontaneous breathing, oscillation frequencies higher than $2-4 \mathrm{~Hz}$ must be used. However, the characteristic rheology of the respiratory tissues below $2 \mathrm{~Hz}$ can be revealed by investigation during voluntary apnoea, as has been shown using a modified set-up in normal subjects between $0.25-5 \mathrm{~Hz}$ [147] and in anaesthetised and paralysed patients from $0.25-32 \mathrm{~Hz}$ [146] or to $26 \mathrm{~Hz}$ [143]. The advantages of the low-frequency range are that the markedly different frequency dependences of the airway and tissue impedance allow the model-based separate estimation of their parameters [148], and that these parameters are more relevant to the mechanical properties manifested 
during spontaneous breathing than those estimated with higher-frequency oscillations. Although the requirement of apnoea limits the applicability of the low-frequency FOT, there are special conditions where its advantages can be exploited. First of all, measurements during suspension of mechanical ventilation in anaesthetised and paralysed subjects for short intervals of oscillation [143, 146] allow the monitoring of the airway and tissue mechanics far more specifically than that offered by commercial respiratory monitors [135].

Another target population of the low-frequency FOT is infants, whose lack of cooperation permits lung function testing only in the sedated state. Here, activation of the endinspiratory Hering-Breuer reflex can be used to evoke the apnoea needed for low-frequency FOT measurements [149]. The post-hyperventilation apnoea permits oscillatory measurements at lower transrespiratory pressures [150]. Further studies with this technique included the establishment of normal values of the mechanical parameters for this age group [151], the evaluation of bronchodilator [152] and bronchoconstrictor provocation tests [153], addressed the alterations in the mechanical properties in wheeze [154] and the contribution of the nasal pathways to Zrs [155].

A special version of the low-frequency FOT uses an optimal ventilatory waveform $(\mathrm{OVW})$ to drive the respiratory system, the combination of mechanical ventilation and impedance estimation [144]. The OVW has been used in studies on the pulmonary and chest wall mechanics in normal subjects before and after bronchoconstriction [156], the broncholytic responses in asthmatics [157] and the inspiratory impedance in flow-limited patients [158].

The technical requirements imposed by the application of FOT during CMV or CPAP, which were addressed briefly above, pertain to all applications of the low-frequency FOT. Most importantly, any leak around the airway opening should be eliminated; a shunt that may not affect $Z$ rs at the medium frequency range would substantially distort the low-frequency values.

\section{High-frequency oscillations}

Similarly to the inclusion of low-frequency components, the elevation of oscillation frequencies above $\sim 100 \mathrm{~Hz}$ reveals new patterns of frequency dependence of $Z$ rs, with the potential of estimating additional mechanical parameters [159-163]. In particular, at frequencies well above $f$ res, $X$ rs crosses zero in the negative direction: this is called the first antiresonant frequency $(f a r, 1)$. Healthy subjects and patients with airway obstruction have been differentiated on the basis of both fres and $f a r, 1$, and the forced spirometry indices have been shown to correlate better with $f$ ar, 1 than with the medium-frequency oscillation parameters [163]. The high-frequency $Z$ rs is dominated by wave propagation processes in the airway tree and much less affected by tissue properties. Although the modelbased analysis of these phenomena remains far from complete [159], current work suggests that far,1 carries information about airway wall compliance, which may be an important descriptor in the understanding of airway instability occurring in wheezing disorders in infancy [162].

Although the low-frequency and high-frequency oscillations reveal different mechanical characteristics of the respiratory system and, hence, require different modelling approaches, combined studies involving both oscillation ranges in the same subjects would certainly be useful, particularly in facilitating the interpretation of the medium-frequency $Z_{\text {rs }}$ data.

Finally, it should be noted that these new applications of FOT have been developed at research level by few laboratories and, therefore, the technical experience gained and the amount of data obtained are still limited.

\section{Conclusions}

Overall, the clinical diagnostic capacity of respiratory impedance measurement by forced oscillation technique is comparable to that of spirometry. With respect to the latter, the main weakness of respiratory impedance determination is that it does not enable the distinction between obstructive and restrictive lung disorders. The main advantages of the forced oscillation technique are that minimal cooperation of the patient and no respiratory manoeuvres are needed; therefore, the measurement of respiratory impedance should be considered whenever spirometry cannot be performed or appears to be unreliable. These qualities of the forced oscillation technique make it an ideal tool to study airway patency during sleep or to monitor the respiratory properties during mechanical ventilation. Additionally, the small amplitude oscillations do not influence the respiratory mechanical properties studied, and this is particularly important when assessing bronchoactive responses. The high time resolution that can be obtained when a single frequency is used makes forced oscillation technique the method of choice to study variations in mechanical properties within the respiratory cycle or temporal changes, such as those induced by a deep inhalation.

Chair and coordinator of the committee: E. Oostveen (University Hospital Antwerp, Belgium).

\section{Appendix A: Glossary of symbols and abbreviations for impedance measurements}

\begin{tabular}{|c|c|c|}
\hline Abbreviation & Description & Unit \\
\hline ao & Airway opening & \\
\hline aw & Airway & \\
\hline bs & Body surface & \\
\hline es & Oesophageal & \\
\hline$f$ & Frequency & $\mathrm{Hz}$ \\
\hline$f_{\text {res }}$ & Resonant frequency & $\mathrm{Hz}$ \\
\hline FRC & Function residual capacity & $\mathrm{L}$ \\
\hline$G$ & Conductance $(1 / R)$ & $\mathrm{L} \cdot \mathrm{kPa}^{-1} \cdot \mathrm{s}^{-1}$ \\
\hline Gaw & Airway conductance (1/Raw) & $\mathrm{L} \cdot \mathrm{kPa}^{-1} \cdot \mathrm{s}^{-1}$ \\
\hline Grs & Total respiratory conductance $(1 / R \mathrm{rs})$ & $\mathrm{L} \cdot \mathrm{kPa}^{-1} \cdot \mathrm{s}^{-1}$ \\
\hline sGaw & $\begin{array}{l}\text { Specific airway conductance } \\
\text { (=Gaw/FRC) }\end{array}$ & $\mathrm{kPa}^{-1} \cdot \mathrm{s}^{-1}$ \\
\hline in & Input & \\
\hline $\mathrm{L}$ & Pulmonary system & \\
\hline$P$ & Pressure & $\mathrm{kPa}$ \\
\hline$R$ & Real part of $Z$ or resistance & $\mathrm{kPa} \cdot \mathrm{s} \cdot \mathrm{L}^{-1}$ \\
\hline rs & Respiratory system & \\
\hline Raw & $\begin{array}{l}\text { Airway resistance measured by } \\
\text { body plethysmography }\end{array}$ & $\mathrm{kPa} \cdot \mathrm{s} \cdot \mathrm{L}^{-1}$ \\
\hline $\mathrm{s} R$ aw & Specific airway resistance (1/sGaw) & $\mathrm{kPa} \cdot \mathrm{s}$ \\
\hline $\operatorname{Rrs} f$ & $\begin{array}{l}\text { Total respiratory resistance } \\
\text { measured at frequency } f\end{array}$ & \\
\hline ti & Tissue & \\
\hline $\operatorname{tr}$ & Transfer & \\
\hline$V^{\prime}$ & Airflow & $L \cdot \mathrm{s}^{-1}$ \\
\hline $\mathrm{W}$ & Chest wall & \\
\hline$X$ & Imaginary part of $Z$ or reactance & $\mathrm{kPa} \cdot \mathrm{s} \cdot \mathrm{L}^{-1}$ \\
\hline$Z$ & Impedance & $\mathrm{kPa} \cdot \mathrm{s} \cdot \mathrm{L}^{-1}$ \\
\hline
\end{tabular}




\begin{abstract}
Acknowledgements. During the Task Force activities, A-M. Lorino passed away. The members of this Task Force are indebted to A-M. Lorino, who besides being a warm personality and personal friend, was also a highly respected colleague who made a major contribution in the field of basic research on the forced oscillation technique and its development in clinical applications.
\end{abstract}

\section{References}

1. van de Woestijne KP, Desager KN, Duiverman EJ, Marchal F. Recommendations for measurement of respiratory input impedance by means of the forced oscillation method. Eur Respir Rev 1994; 4: 235-237.

2. DuBois AB, Brody AW, Lewis DH, Burgess BF. Oscillation mechanics of lungs and chest in man. J Appl Physiol 1956; 8: 587-594.

3. Peslin R, Fredberg JJ. Oscillation mechanics of the respiratory system. In: Macklem PT, Mead J, eds. Handbook of Physiology. The Respiratory System. Mechanics of Breathing. Bethesda, MD, American Physiological Society, 1986; pp. 145-178.

4. Pride NB. Forced oscillation techniques for measuring mechanical properties of the respiratory system. Thorax 1992; 47: 317-320.

5. Marchal F, Loos N. Respiratory oscillation mechanics in infant and preschool children. Eur Respir Mon 1997; 5: 5887.

6. Navajas D, Farré R. Forced oscillation technique: from theory to clinical applications. Monaldi Arch Chest Dis 2001; 56: $555-562$.

7. MacLeod D, Birch M. Respiratory input impedance measurement: forced oscillation methods. Med Biol Eng Comput 2001; 39: 505-516.

8. Peslin R, Duvivier C, Didelon J, Gallina C. Respiratory impedance measured with head generator to minimize upper airway shunt. J Appl Physiol 1985; 59: 1790-1795.

9. van de Woestijne KP, Franken H, Cauberghs M, Làndsér FJ, Clément J. A modification of the forced oscillation technique. In: Hutàs I, Debreczeni LA, eds. Respiration. Budapest, Adv Physiol Sci, 1981; pp. 655-660.

10. Peslin R, Jardin P, Duvivier C, Begin P. In-phase requirements for measuring respiratory input impedance. $J$ Applied Physiol 1984; 56: 804-809.

11. Hellinckx J, Cauberghs M, De Boeck K, Demedts M. Evaluation of impulse oscillation system: comparison with forced oscillation technique and body plethysmography. Eur Respir J 2001; 18: 564-570.

12. Rotger M, Peslin R, Farré R, Duvivier C. Influence of amplitude, phase and frequency content of pseudorandom pressure input on impedance data and their variability. Eur Respir Rev 1991; 1: 178-182.

13. Daróczy B, Hantos Z. Generation of optimum pseudorandom signals for respiratory impedance measurements. Int J Biomed Comput 1990; 25: 21-31.

14. Farré R, Rotger M, Navajas D. Optimized estimation of respiratory impedance by signal averaging in the time domain. J Appl Physiol 1992; 73: 1181-1189.

15. Navajas D, Farré R, Rotger M, Peslin R. A new estimate to minimize the error due to breathing in the measurements of respiratory impedance. IEEE Trans Biomed Eng 1988; 35: 1001-1005.

16. Daróczy B, Hantos Z. An improved forced oscillatory estimation of respiratory impedance. Int J Biomed Comput 1982; 1982: 221-225.

17. Lorino H, Mariette C, Karouia M, Lorino AM. Influence of signal processing on estimation of respiratory impedance. J Appl Physiol 1993; 74: 215-223.

18. Michaelson ED, Grassman ED, Peters WR. Pulmonary mechanics by spectral analysis of forced random noise. $J$ Clin Invest 1975; 56: 1210-1230.

19. Cauberghs M, Van de Woestijne KP. Effect of upper airway shunt and series properties on respiratory impedance measurements. J Appl Physiol 1989; 66: 2274-2279.

20. Peslin R, Duvivier C, Gallina C, Cervantes P. Upper airway artefact in respiratory impedance measurements. Am Rev Respir Dis 1985; 132: 712-714.

21. Marchal F, Haouzi P, Peslin R, Duvivier C, Gallina C. Mechanical properties of the upper airway wall in children and their influence on respiratory impedance measurements. Pediatr Pulmonol 1992; 13: 28-33.

22. Peslin R, Duvivier C, Jardin P. Upper airway walls impedance measured with head plethysmograph. J Appl Physiol 1984; 57: 596-600.

23. Marchal F, Mazurek H, Habib M, Duvivier C, Derelle J, Peslin R. Input respiratory impedance to estimate airway hyperreactivity in children: standard method versus head generator. Eur Respir J 1994; 7: 601-607.

24. Govaerts E, Cauberghs M, Demedts M, Van de Woestijne KP. Head generator versus conventional technique in respiratory input impedance measurements. Eur Respir Rev 1994; 4: 143-149.

25. Farré R, Rotger M, Marchal F, Peslin R, Navajas D. Assessment of bronchial reactivity by forced oscillation admittance avoids the upper airway artefact. Eur Respir $J$ 1999; 13: 761-766

26. Peslin R, Teculescu D, Locuty J, Gallina C, Duvivier C. Normal values of the total respiratory input impedance with the head generator technique. Eur Resp Rev 1994; 4: 138-142.

27. Mazurek HK, Marchal F, Derelle J, Hatahet R, MoneretVautrin D, Monin P. Specificity and sensitivity of respiratory impedance in assessing reversibility of airway obstruction in children. Chest 1995; 107: 996-1002.

28. Làndsér FJ, Clément $\mathbf{J}$, Van de Woestijne KP. Normal values of total respiratory resistance and reactance determined by forced oscillations: influence of smoking. Chest 1982; 81: 586-591.

29. Clément J, Làndsér FJ, van de Woestijne KP. Total resistance and reactance in patients with respiratory complaints with and without airways obstruction. Chest 1983; 83: 215-220.

30. Gimeno F, van der Weele LT, Koëter GH, van Altena R. Forced oscillation technique. Reference values for total respiratory resistance obtained with the Siemens Siregnost FD5. Ann Allergy 1992; 68: 155-158.

31. Pasker HG, Mertens I, Clément J, Van de Woestijne KP. Normal values of total respiratory input resistance and reactance for adult men and women. Eur Respir Rev 1994; 4: 134-137.

32. Pasker HG, Schepers R, Clément J, van de Woestijne KP. Total respiratory impedance measured by means of the forced oscillation technique in subjects with and without respiratory complaints. Eur Respir J 1996; 9: 131-139.

33. Zerah F, Lorino AM, Lorino H, Harf A, Macquin-Mavier I. Forced oscillation technique vs spirometry to assess bronchodilatation in patients with asthma and COPD. Chest 1995; 108: 41-47.

34. Duiverman EJ, Clément J, van de Woestijne KP, Neijens HJ, van den Bergh ACM, Kerrebijn KF. Forced oscillation technique. Reference values for resistance and reactance over a frequency spectrum of $2-26 \mathrm{~Hz}$ in healthy children aged 2.3-12.5 years. Bull Eur Physiopathol Respir 1985; 21: 171-178.

35. Cuijpers CE, Wesseling G, Swaen GM, Wouters EF. Frequency dependence of oscillatory resistance in healthy primary school children. Respiration 1993; 60: 149-154.

36. Hantos Z, Daróczy B, Gyurkovits K. Total respiratory impedance in healthy children. Pediatr Pulmonol 1985; 1: 9198.

37. Cogswell JJ. Forced oscillation technique for determination of resistance to breathing in children. Arch Dis Child 1973; 48: $259-266$ 
38. Hordvik NL, König P, Morris DA, Kreutz C, Pimmel RL. Normal values for forced oscillatory respiratory resistance in children. Pediatr Pulmonol 1985; 1: 145-148.

39. Lebecque P, Desmond K, Swartebroeckx Y, Dubois P, Lulling J, Coates A. Measurement of respiratory system resistance by forced oscillation in normal children: a comparison with spirometric values. Pediatr Pulmonol 1991; 10: 117-122.

40. Solymar L, Aronsson PH, Bake B, Bjure J. Respiratory resistance and impedance magnitude in healthy children aged 2-18 years. Pediatr Pulmonol 1985; 1: 134-140.

41. Stanescu D, Moavero NE, Veriter C, Brasseur L. Frequency dependence of respiratory resistance in healthy children. J Appl Physiol 1979; 47: 268-272.

42. Williams SP, Fullton JM, Tsai MJ, Pimmel RL, Collier AM. Respiratory impedance and derived parameters in young children by forced random noise. J Appl Physiol 1979; 47: 169-174.

43. Mansell A, Levison H, Kruger K, Tripp TL. Measurement of respiratory resistance in children by forced oscillations. Am Rev Respir Dis 1972; 106: 710-714.

44. Hellinckx J, De Boeck K, Bande-Knops J, van der Poel M, Demedts M. Bronchodilator response in 3-6.5 years old healthy and stable asthmatic children. Eur Respir J 1998; 12: 438-443.

45. Ducharme FM, Davis GM, Ducharme GR. Pediatric reference values for respiratory resistance measured by forced oscillation. Chest 1998; 113: 1322-1328.

46. Mazurek H, Willim G, Marchal F, Haluszka J, Tomalak W. Input respiratory impedance measured by head generator in preschool children. Pediatr Pulmonol 2000; 30: 47-55.

47. Willim G, Mazurek H, Kurzawa R, et al. Reference values of lung function measurements in polish children and adolescents. Part 1: respiratory resistance and reactance measured by forced oscillation technique (FOT). J Int Rev Allergol Clin Immunol 2000; 6: 70-78.

48. Neild JE, Twort $\mathrm{CH}$, Chinn S, et al. The repeatability and validity of respiratory resistance measured by the forced oscillation technique. Respir Med 1989; 83: 111-118.

49. van den Elshout FJ, van de Woestijne KP, Folgering HT Variations of respiratory impedance with lung volume in bronchial hyperreactivity. Chest 1990; 98: 358-364.

50. Snashall PD, Parker S, Phil M, Ten Haave P, Simmons D, Noble MIM. Use of an impedance meter for measuring airways responsiveness to histamine. Chest 1991; 99: 11831185.

51. Gimeno F, van der Weele LT, Koëter GH, de Monchy JGR, van Altena R. Variability of forced oscillation (Siemens Siregnost FD 5) measurements of total respiratory resistance in patients and healthy subjects. Ann Allergy 1993; 71: 56-60.

52. van Noord JA, Smeets J, Clément J, van de Woestijne KP, Demedts M. Assessment of reversibility of airflow obstruction. Am J Respir Crit Care Med 1994; 150: 551-554.

53. Solymar L, Aronsson PH, Engstrom I, Bake B, Bjure J. Forced oscillation technique and maximum expiratory flows in bronchial provocation tests in children. Eur J Respir Dis 1984; 65: 486-495.

54. Timonen KL, Randell JT, Salonen RO, Pekkanen J. Shortterm variations in oscillatory and spirometric lung function indices among school children. Eur Respir J 1997; 10: 82-87.

55. Buhr W, Jorres R, Berdel D, Landser FJ. Correspondence between forced oscillation and body plethysmography during bronchoprovocation with carbachol in children. Pediatr Pulmonol 1990; 8: 280-288.

56. Lenney W, Milner AD. At what age do bronchodilator drugs work? Arch Dis Child 1978; 53: 532-735.

57. Delacourt C, Lorino H, Herve-Guillot M, Reinert P, Harf A, Housset B. Use of the forced oscillation technique to assess airway obstruction and reversibility in children. Am J Respir Crit Care Med 2000; 161: 730-736.

58. Tomalak W, Elbousefi A, Kurzawa R, Doniec Z. Diurnal variations of respiratory system resistance and compliance derived from input impedance in asthmatic children. Respir Physiol 2000; 123: 101-108.

59. van Noord JA, Clément J, van de Woestijne KP, Demedts M Total respiratory resistance and reactance in patients with asthma, chronic bronchitis, and emphysema. Am Rev Respir Dis 1991; 143: 922-927.

60. Govaerts E, Demedts M, Van de Woestijne KP. Total respiratory impedance and early emphysema. Eur Respir $J$ 1993; 6: 1181-1185.

61. Wesseling GJ, Wouters EF. Analysis of respiratory impedance characteristics in chronic bronchitis. Respiration 1992; 59: 81-88.

62. van Noord JA, Cauberghs $M$, van de Woestijne KP, Demedts M. Total respiratory resistance and reactance in ankylosing spondylitis and kyphoscoliosis. Eur Respir J 1991; 4: 945-951.

63. Horan $\mathrm{T}$, Mateus S, Beraldo $\mathrm{P}$, et al. Forced oscillation technique to evaluate tracheostenosis in patients with neurological injury. Chest 2001; 120: 69-73.

64. van Noord JA, Clément J, Cauberghs M, Mertens I, van de Woestijne KP, Demedts M. Total respiratory resistance and reactance in patients with diffuse interstitial lung disease. Eur Respir J 1989; 2: 846-852.

65. Zerah F, Harf A, Perlemuter L, Lorino H, Lorino AM, Atlan G. Effects of obesity on respiratory resistance. Chest 1993; 103: 1470-1476.

66. Lebecque P, Stanescu D. Respiratory resistance by the forced oscillation technique in asthmatic children and cystic fibrosis patients. Eur Respir J 1997; 10: 891-895.

67. Holmgren D, Engstrom I, Bjure J, Sixt R, Aberg N Respiratory resistance and transcutaneous PO2 during histamine provocation in children with bronchial asthma. Pediatr Pulmonol 1993; 15: 168-174.

68. Ducharme FM, Davis GM. Measurement of respiratory resistance in the emergency department: feasibility in young children with acute asthma. Chest 1997; 111: 1519-1525.

69. Chalut DS, Ducharme FM, Davis GM. The preschool respiratory assessment measure (PRAM): a responsive index of acute asthma severity. J Pediatr 2000; 137: 762-768.

70. Solymar L, Aronsson PH, Sixt R. The forced oscillation technique in children with respiratory disease. Pediatr Pulmonol 1985; 1: 256-261.

71. Hellinckx J, De Boeck K, Demedts M. No paradoxical bronchodilator response with forced oscillation technique in children with cystic fibrosis. Chest 1998; 113: 55-59.

72. Duiverman EJ, Den Boer JA, Roorda RJ, Rooyackers CMHM, Valstar M, Kerrebijn KF. Lung function and bronchial responsiveness measured by forced oscillometry after bronchopulmonary dysplasia. Arch Dis Child 1988; 63: 727-732.

73. Malmberg LP, Mieskonen S, Pelkonen A, Kari A, Sovijärvi ARA, Turpeinen M. Lung function measured by the oscillometric method in prematurely born children with chronic lung disease. Eur Respir J 2000; 16: 598-603.

74. Carvalhaes-Neto N, Lorino H, Gallinari C, et al. Cognitive function and assessment of lung function in the elderly. Am J Respir Crit Care Med 1995; 152: 1611-1615.

75. Coe CI, Watson A, Joyce H, Pride NB. Effects of smoking on changes in respiratory resistance with increasing age. Clin Sci (Colch) 1989; 76: 487-494.

76. Brochard L, Pelle G, de Palmas J, et al. Density and frequency dependence of resistance in early airway obstruction. Am Rev Respir Dis 1987; 135: 579-584.

77. Peslin R, Pham QT, Teculescu D, Gallina C, Duvivier C Comparative value of respiratory input and transfer impedances in field studies. Bull Eur Physiopathol Respir 1987; 23: $37-42$.

78. Pham QT, Bourgkard E, Chau N, et al. Forced oscillation technique (FOT): a new tool for epidemiology of occupational lung diseases? Eur Respir J 1995; 8: 1307-1313.

79. Iwatsubo $\mathrm{Y}$, Lorino $\mathrm{H}$, Hubert $\mathrm{C}$, et al. Measurement of respiratory impedance by forced oscillation: comparison of 
the standard and head generator methods. Eur Respir J 1994; 7: 901-906.

80. Pasker HG, Peeters M, Genet P, Clément J, Nemery B, van de Woestijne KP. Short-term ventilatory effects in workers exposed to fumes containing zincoxide: comparison of forced oscillation technique with spirometry. Eur Respir J 1997; 10: 1523-1529.

81. Pairon JC, Iwatsubo Y, Hubert C, et al. Measurement of bronchial responsiveness by forced oscillation technique in occupational epidemiology. Eur Respir J 1994; 7: 484- 489.

82. Bohadana AB, Peslin R, Megherbi SE, et al. Dose-response slope of forced oscillation and forced expiratory parameters in bronchial challenge testing. Eur Respir J 1999; 13: 295300 .

83. Santoli F, Zerah F, Vasile N, Bachir D, Galacteros F, Atlan G. Pulmonary function in sickle cell disease with or without acute chest syndrome. Eur Respir J 1998; 12: 1124 1129.

84. Làndsér FJ, Nagels J, van de Woestijne KP. Implementation by means of microprocessor techniques for the measurement of total respiratory impedance during spontaneous breathing. Prog Resp Res 1979; 11: 135-143.

85. Wouters EF, Verschoof AC, Polko AH, Visser BF. Impedance measurements of the respiratory system before and after salbutamol in COPD patients. Respir Med 1989; 83: 309-313.

86. Ducharme FM, Davis GM. Respiratory resistance in the emergency department: a reproducible and responsive measure of asthma severity. Chest 1998; 113: 1566-1572.

87. Wanner A, Zarzecki S, Marks MB. Continuous measurement of respiratory resistance in asthmatic children. Respiration 1977; 34: 61-68.

88. Menon P, Hilman BC, Menon V, Bairnsfather L. Assessment of response to oral metaproterenol sulfate by forced oscillation in young children. Ann Allergy 1988; 60: 547-551.

89. Konig P, Gayer D, Kantak A, Kreutz C, Douglass B, Hordvik NL. A trial of metaproterenol by metered-dose inhaler and two spacers in preschool asthmatics. Pediatr Pulmonol 1988; 5: 247-251.

90. Groggins RC, Milner AD, Stokes GM. Bronchodilator effects of clemastine, ipratropium, bromide, and salbutamol in preschool children with asthma. Arch Dis Child 1981; 56: 342-344.

91. Nussbaum E, Eyzaguirre M, Galant SP. Dose-response relationship of inhaled metaproterenol sulfate in preschool children with mild asthma. Pediatrics 1990; 85: 1072-1075.

92. Pauwels JH, Desager KN, Creten WL, Van der Veken J, Van Bever HP. Study of the bronchodilating effect of three doses of nebulized oxitropium bromide in asthmatic preschool children using the forced oscillation technique. Eur J Pediatr 1997; 156: 329-332.

93. Crapo RO, Casaburi R, Coates AL, et al. Guidelines for methacholine and exercise challenge testing-1999. This official statement of the American Thoracic Society was adopted by the ATS Board of Directors, July 1999. Am J Respir Crit Care Med 2000; 161: 309-329.

94. Sterk PJ, Fabbri LM, Quanjer PH, et al. Airway responsiveness. Standardized challenge testing with pharmacological, physical and sensitizing stimuli in adults. Eur Respir $J$ 1993; 6: Suppl. 16, 53-83.

95. Wesseling GJ, Vanderhoven-Augustin IM, Wouters EF. Forced oscillation technique and spirometry in cold air provocation tests. Thorax 1993; 48: 254-259.

96. Tamura G, Mue S, Ishihara T, Takishima T. The single exposure method for inhalation challenge with allergen. J Allergy Clin Immunol 1985; 75(1 Pt 1): 47-54.

97. Weersink EJ, vd Elshout FJ, van Herwaarden CV, Folgering H. Bronchial responsiveness to histamine and methacholine measured with forced expirations and with the forced oscillation technique. Respir Med 1995; 89: 351-356.

98. van Noord JA, Clément J, van de Woestijne KP, Demedts M. Total respiratory resistance and reactance as a measurement of response to bronchial challenge with histamine. Am Rev Respir Dis 1989; 139: 921-926.

99. Schmekel B, Smith HJ. The diagnostic capacity of forced oscillation and forced expiration techniques in identifying asthma by isocapnic hyperpnoea of cold air. Eur Respir $J$ 1997; 10: 2243-2249.

100. Chinet T, Pelle G, Macquin-Mavier I, Lorino H, Harf A. Comparison of the dose-response curves obtained by forced oscillation and plethysmography during carbachol inhalation. Eur Respir J 1988; 1: 600-605.

101. Pennings HJ, Wouters EF. Effect of inhaled beclomethasone dipropionate on isocapnic hyperventilation with cold air in asthmatics, measured with forced oscillation technique. Eur Respir J 1997; 10: 665-671.

102. Manço JC, Hyatt RE, Rodarte JR. Respiratory impedance in normal humans: effects of bronchodilatation and bronchoconstriction. Mayo Clin Proc 1987; 62: 487-497.

103. Sekizawa K, Yanai M, Shimizu Y, Sasaki H, Takishima T. Serial distribution of bronchoconstriction in normal subjects. Methacholine versus histamine. Am Rev Respir Dis 1988, 137: $1312-1316$

104. Sekizawa K, Sasaki H, Shimizu Y, Takishima T. Doseresponse effects of methacholine in normal and in asthmatic subjects. Relationship between the site of airway response and overall airway hyperresponsiveness. Am Rev Respir Dis 1986; 133: 593-599.

105. Wang YT, Coe CI, Pride NB. Effect on histamine responsiveness of reducing airway dimensions by altering posture. Thorax 1990; 45: 530-535.

106. Saito H, Nishimura M, Shinano H, Sato F, Miyamoto K, Kawakami Y. Effect of mild hypoxia on airway responsiveness to methacholine in subjects with airway hyperresponsiveness. Chest 1999; 116: 1653-1658.

107. Fujimori K, Satoh M, Arakawa M. Ventilatory response to continuous incremental changes in respiratory resistance in patients with mild asthma. Chest 1996; 109: 1525-1531.

108. Duiverman EJ, Neijens HJ, Van der Snee-van Smaalen M, Kerrebijn KF. Comparison of forced oscillometry and forced expirations for measuring dose-related responses to inhaled methacholine in asthmatic children. Bull Eur Physiopathol Respir 1986; 22: 433-436.

109. Lebecque P, Spier S, Lapierre JG, Lamarre A, Zinman R, Coates AL. Histamine challenge test in children using forced oscillation to measure total respiratory resistance. Chest 1987; 92: 313-318.

110. Duiverman EJ, Neijens HJ, van Strik R, van der Snee-van Smaalen M, Kerrebijn KF. Bronchial responsiveness in asthmatic children aged 3 to 8 years measured by forced pseudo-random noise oscillometry. Bull Eur Physiopathol Respir 1986; 22: 27-33.

111. Wilson NM, Bridge P, Phagoo SB, Silverman M. The measurement of methacholine responsiveness in 5 year old children: three methods compared. Eur Respir J 1995; 8: 364-370.

112. Klug B, Bisgaard $\mathrm{H}$. Measurement of lung function in awake 2-4-year-old asthmatic children during methacholine challenge and acute asthma: a comparison of the impulse oscillation technique, the interrupter technique, and transcutaneous measurement of oxygen versus whole-body plethysmography. Pediatr Pulmonol 1996; 21: 290-300.

113. Bisgaard H, Klug B. Lung function measurement in awake young children. Eur Respir J 1995; 8: 2067-2075.

114. Bouaziz N, Beyaert C, Gauthier R, Monin P, Peslin R, Marchal F. Respiratory system reactance as an indicator of the intrathoracic airway response to methacholine in children. Pediatr Pulmonol 1996; 22: 7-13.

115. Gaultier C, Fletcher ME, Beardsmore C, England S, Motoyama E. Respiratory function measurements in infants: measurement conditions. Eur Respir J 1995; 8: 1057-1066.

116. Desager KN, Marchal F, Van de Woestijne KP. Forced oscillation technique. In: Stocks J, Sly PD, Tepper RS, Morgan WJ, eds. Infant respiratory function testing. New York, Wiley-Liss, 1996; pp. 355-378. 
117. Farré R, Navajas D, Peslin R, Rotger M, Duvivier C. A correction procedure for the asymmetry of differential pressure transducers in respiratory impedance measurements. IEEE Trans Biomed Eng 1989; 36: 1137-1140.

118. Desager KN, Buhr W, Willemen M, et al. Measurement of total respiratory impedance in infants by the forced oscillation technique. J Appl Physiol 1991; 71: 770-776.

119. Desager KN, Cauberghs M, Van de Woestijne KP. Twopoint calibration procedure of the forced oscillation technique. Med Biol Eng Comput 1997; 35: 752-756.

120. Marchal F, Peslin R, Duvivier C, Gallina C, Crance JP. Mechanics of the ventilatory system in sedated infants: Forced oscillations versus singlebreath method. Pediatr Pulmonol 1988; 5: 19-26.

121. Marchal F, Peslin R, Duvivier C, Gallina C, Crance JP. Measurement of ventilatory mechanical impedance in infants using a head pressure generator. Pediatr Pulmonol 1989; 7: 209-216.

122. Desager KN, Cauberghs M, Naudts J, van de Woestijne KP. Influence of upper airway shunt on total respiratory impedance in infants. J Appl Physiol 1999; 87: 902-909.

123. Desager KN, Willemen M, Van Bever HP, De Backer W, Vermeire PA. Evaluation of nasal impedance using the forced oscillation technique in infants. Pediatr Pulmonol 1991; 11: 1-7.

124. Dorkin HL, Stark AR, Werthammer JW, Strieder DJ, Fredberg JJ, Frantz IDR. Respiratory system impedance from 4 to $40 \mathrm{~Hz}$ in paralyzed intubated infants with respiratory disease. J Clin Invest 1983; 72: 903-910.

125. Gauthier R, Beyaert C, Feillet F, Monin P, Marchal F. Respiratory oscillation mechanics in infants with bronchiolitis during mechanical ventilation. Pediatr Pulmonol 1998; 25: $18-31$.

126. Martinez FD, Morgan WJ, Wright AL, Holberg CJ, Taussig LM. Diminished lung function as a predisposing factor for wheezing respiratory illness in infants. New Engl J Med 1988; 319: 1112-1117.

127. Desager KN, Van Bever HP, Willemen M, De Backer W, Vermeire PA. Functional residual capacity and total respiratory system impedance in wheezing infants. Pediatr Pulmonol 1994; 17: 354-358.

128. Soto ME, Sly PD, Uren E, Taussig LM, Landau LI. Bronchodilator response during acute viral bronchiolitis in infancy. Pediatr Pulmonol 1985; 2: 85-90.

129. van Bever HP, Desager KN, Pauwels JH, Wojciechowski M, Vermeire PA. Aerosolised furosemide in wheezy infants: a negative report. Pediatr Pulmonol 1995; 20: 16-20.

130. Peslin R, Felicio da Silva J, Duvivier C, Chabot F. Respiratory mechanics studied by forced oscillations during artificial ventilation. Eur Respir J 1993; 6: 772-784.

131. Lanteri CJ, Kano S, Duncan AW, Sly PD. Changes in respiratory mechanics in children undergoing cardiopulmonary bypass. Am J Respir Crit Care Med 1995; 152: 1893-1900.

132. Farré R, Ferrer M, Rotger M, Torres A, Navajas D. Respiratory mechanics in ventilated COPD patients: forced oscillation versus occlusion techniques. Eur Respir J 1998; 12: 170-176.

133. Farré R, Mancini M, Rotger M, Ferrer M, Roca J, Navajas D. Oscillatory resístance measured during noninvasive proportional assist ventilation. Am J Respir Crit Care Med 2001; 164: 790-794.

134. Beydon L, Malassine P, Lorino AM, et al. Respiratory resistance by end-inspiratory occlusion and forced oscillations in intubated patients. J Appl Physiol 1996; 80: 1105-1111.

135. Babik B, Peták F, Asztalos T, Deák ZI, Bogáts G, Hantos Z. Components of respiratory resistance monitored in mechanically ventilated patients. Eur Respir J 2002; 20: 1538-1544.

136. Badia JR, Farre R, Montserrat JM, et al. Forced oscillation technique for the evaluation of severe sleep apnoea/hypopnoea syndrome: a pilot study. Eur Respir J 1998; 11: 1128-1134.

137. Lorino AM, Lofaso F, Duizabo D, et al. Respiratory resistive impedance as an index of airway obstruction during nasal continuous positive airway pressure titration. $\mathrm{Am}$ J Respir Crit Care Med 1998; 158: 1465-1470.

138. Navajas D, Farré R, Rotger M, Badia R, Puig-de-Morales M, Montserrat JM. Assessment of airflow obstruction during CPAP by means of forced oscillation in patients with sleep apnea. Am J Respir Crit Care Med 1998; 157: $1526-1530$.

139. Randerath WJ, Parys K, Feldmeyer F, Sanner B, Ruhle KH. Self-adjusting nasal continuous positive airway pressure therapy based on measurement of impedance: A comparison of two different maximum pressure levels. Chest 1999; 116: 991-999.

140. Montserrat JM, Badia JR, Farré R, Ballester E, Hernandez L, Navajas D. Routine application of the forced oscillation technique (FOT) for CPAP titration in the sleep apnea/ hypopnea syndrome. Am J Respir Crit Care Med 1999; 160: $1550-1554$.

141. Jensen A, Atileh H, Suki B, Ingenito EP, Lutchen KR. Airway caliber in healthy and asthmatic subjects: effects of bronchial challenge and deep inspirations. J Appl Physiol 2001; 91: 506-515.

142. Schweitzer C, Moreau-Colson C, Marchal F. Respiratory impedance response to a deep inhalation in asthmatic children with spontaneous airway obstruction. Eur Respir $J$ 2002; 19: 1020-1025.

143. Farré R, Ferrer M, Rotger M, Navajas D. Servocontrolled generator to measure respiratory impedance from 0.25 to $26 \mathrm{~Hz}$ in ventilated patients at different PEEP levels. Eur Respir J 1995; 8: 1222-1227.

144. Lutchen KR, Yang K, Kaczka DW, Suki B. Optimal ventilation waveforms for estimating low-frequency respiratory impedance. J Appl Physiol 1993; 75: 478-488.

145. Farré R, Rotger M, Montserrat JM, Navajas D. A system to generate simultaneous forced oscillation and continuous positive airway pressure. Eur Respir J 1997; 10: 1349-1353.

146. Navajas D, Farré R, Canet J, Rotger M, Sanchis J. Respiratory input impedance in anesthetized paralyzed patients. J Appl Physiol 1990; 69: 1372-1379.

147. Hantos Z, Daróczy B, Suki B, Galgóczy G, Csendes T Forced oscillatory impedance of the respiratory system at low frequencies. J Appl Physiol 1986; 60: 123-132.

148. Hantos Z, Daróczy B, Suki B, Nagy S, Fredberg JJ. Input impedance and peripheral inhomogeneity of dog lungs. J Appl Physiol 1992; 72: 168-178.

149. Sly PD, Hayden MJ, Peták F, Hantos Z. Measurement of low-frequency respiratory impedance in healthy infants. $\mathrm{Am}$ J Respir Crit Care Med 1996; 154: 161-166.

150. Peták F, Hayden MJ, Hantos Z, Sly PD. Volume dependence of respiratory impedance in infants. Am J Respir Crit Care Med 1997; 156: 1172-1177.

151. Hall GL, Hantos Z, Peták F, et al. Airway and respiratory tissue mechanics in normal infants. Am J Respir Crit Care Med 2000; 162: 1397-1402.

152. Hayden MJ, Petak F, Hantos Z, Hall G, Sly PD. Using low-frequency oscillation to detect bronchodilator responsiveness in infants. Am J Respir Crit Care Med 1998; 157: 574-579.

153. Hall GL, Hantos Z, Sly PD. Altered respiratory tissue mechanics in asymptomatic wheezy infants. Am J Respir Crit Care Med 2001; 164: 1387-1391.

154. Hall GL, Hantos Z, Wildhaber JH, Peták F, Sly PD. Methacholine responsiveness in infants assessed with lowfrequency forced oscillation and forced expiration techniques. Thorax 2001; 56: 42-47.

155. Hall GL, Hantos Z, Wildhaber JH, Sly PD. Contribution of nasal pathways to low-frequency respiratory impedance in infants. Thorax 2002; 57: 396-399.

156. Kaczka DW, Ingenito EP, Suki B, Lutchen KR. Partitioning airway and lung tissue resistances in humans: effects of bronchoconstriction. J Appl Physiol 1997; 82: 1531-1541.

157. Kaczka DW, Ingenito EP, Israel E, Lutchen KR. Airway 
and lung tissue mechanics in asthma. Effects of albuterol. Am J Respir Crit Care Med 1999; 159: 169-178.

158. Kaczka DW, Ingenito EP, Lutchen KR. Technique to determine inspiratory impedance during mechanical ventilation: implications for flow limited patients. Ann Biomed Eng 1999; 27: 340-355.

159. Frey U, Suki B, Kraemer R, Jackson AC. Human respiratory input impedance between 32 and $800 \mathrm{~Hz}$, measured by interrupter technique and forced oscillations. J Appl Physiol 1997; 82: 1018-1023.

160. Frey U, Silverman M, Kraemer R, Jackson AC. Highfrequency respiratory impedance measured by forced-oscillation technique in infants. Am J Respir Crit Care Med 1998; 158: 363-370.

161. Frey U, Jackson AC, Silverman M. Differences in airway wall compliance as a possible mechanism for wheezing disorders in infants. Eur Respir J 1998; 12: 136-142.

162. Frey U, Silverman M, Kraemer R, Jackson AC. High frequency input impedance in infants assessed with the high speed interrupter technique. Eur Respir J 1998; 12: 148-158.

163. Chalker RB, Celli BR, Habib RH, Jackson AC. Respiratory input impedance from 4 to $256 \mathrm{~Hz}$ in normals and chronic airflow obstruction: comparisons and correlations with spirometry. Am Rev Respir Dis 1992; 146: 570-576. 